University of Wollongong

Research Online

Faculty of Engineering and Information

Faculty of Engineering and Information

Sciences - Papers: Part B

Sciences

2018

Behavior of High-Strength Concrete Columns Reinforced with Galvanized Steel Equal-Angle Sections under Different Loading Conditions

Muhammad N. S Hadi

University of Wollongong, mhadi@uow.edu.au

Ayoob Ibrahim

University of Wollongong, aaii884@uowmail.edu.au

M Neaz Sheikh

University of Wollongong, msheikh@uow.edu.au

Follow this and additional works at: https://ro.uow.edu.au/eispapers1

Part of the Engineering Commons, and the Science and Technology Studies Commons

Research Online is the open access institutional repository for the University of Wollongong. For further information contact the UOW Library: research-pubs@uow.edu.au 


\title{
Behavior of High-Strength Concrete Columns Reinforced with Galvanized Steel Equal-Angle Sections under Different Loading Conditions
}

\author{
Abstract \\ Experimental results are presented for a new method of reinforcing concrete columns with galvanized \\ steel equal-angle (GSEA) sections. For the same cross-sectional area, a GSEA section has a higher \\ second moment of area than a conventional steel bar, which leads to a higher bending stiffness of the \\ GSEA reinforced concrete member. In addition, the area of confined concrete is higher in GSEA reinforced \\ concrete members than in steel bar reinforced members, which results in higher strength and ductility. \\ The experimental program involved testing of 20 square, high-strength concrete (HSC) specimens under \\ concentric axial load, eccentric axial load, and four-point loading. The specimens were reinforced \\ longitudinally with either four N12 (12-mm-diameter deformed steel) bars or four GSEA sections and \\ transversely with R10 (10-mm-diameter plain steel) bars. The specimens were $800 \mathrm{~mm}$ high with a $210 \mathrm{x}$ \\ $210 \mathrm{~mm}$ square cross section. Fifteen specimens were tested under either a concentric or eccentric axial \\ load. The remaining five specimens were tested under four-point loading. Effects of the type of \\ longitudinal reinforcement, spacing of transverse reinforcement, and loading conditions on the behavior \\ of HSC specimens were investigated and discussed. Experimental results showed that, in general, \\ specimens reinforced with GSEA sections had higher load-carrying capacities than the specimens \\ reinforced with steel bars. In addition, the postpeak load-deformation behavior was observed to be more \\ pronounced in specimens reinforced with GSEA sections than in specimens reinforced with steel bars.

\section{Disciplines} \\ Engineering | Science and Technology Studies

\section{Publication Details} \\ Hadi, M. N. S., Ibrahim, A. A. \& Sheikh, M. Neaz. (2018). Behavior of High-Strength Concrete Columns \\ Reinforced with Galvanized Steel Equal-Angle Sections under Different Loading Conditions. Journal of \\ Structural Engineering, 144 (7), 04018070-1-04018070-18.
}


Originally published as:

Hadi, M. N. S., Ibrahim, A. A. \& Sheikh, M. Neaz. (2018). Behavior of High-Strength Concrete Columns Reinforced with Galvanized Steel Equal-Angle Sections under Different Loading Conditions. Journal of Structural Engineering, 144 (7), 04018070-1-04018070-18.

\title{
1 Behavior of High Strength Concrete Columns Reinforced with Galvanized
}

\section{Steel Equal Angle (GSEA) Sections under Different Loading Conditions}

\author{
Muhammad N.S. $\operatorname{Hadi}^{1}$ F. ASCE, Ayoob A. Ibrahim² ${ }^{2}$ M. Neaz Sheikh ${ }^{3}$
}

\section{$4 \quad$ Abstract}

5 This paper presents experimental results of a new method of reinforcing concrete columns with galvanized steel equal angle (GSEA) sections. For the same cross-sectional area, a GSEA section has a higher second moment of area than a conventional steel bar, which leads to a higher bending stiffness of the GSEA reinforced concrete member. In addition, the area of confined concrete is higher in GSEA reinforced concrete members than in steel bar reinforced members, which results in higher strength and ductility. The experimental program involved testing of twenty square high strength concrete (HSC) specimens under concentric axial load, eccentric axial load and four-point loading. The specimens were reinforced longitudinally with either four N12 (12 mm diameter deformed steel) bars or four GSEA sections and transversely with R10 (10 mm diameter plain steel) bars. The specimens were $800 \mathrm{~mm}$ high with $210 \mathrm{~mm} \times 210 \mathrm{~mm}$ square cross-section. Fifteen specimens were tested under either concentric or eccentric axial load. The remaining five specimens were tested under four-point loading. The effects of the type of longitudinal reinforcement, the spacing of transverse reinforcement and loading conditions on the behavior of HSC specimens were investigated and discussed. The experimental results showed that, in general, specimens reinforced with GSEA sections had higher load carrying capacities than the specimens

\footnotetext{
${ }^{1}$ Associate Professor, School of Civil, Mining and Environmental Engineering, University of Wollongong, NSW 2522, Australia, Email: mhadi@ uow.edu.au, Corresponding Author

${ }^{2}$ Ph.D. Candidate, School of Civil, Mining and Environmental Engineering, University of Wollongong, NSW 2522, Australia, Email: aaii884@uowmail.edu.au

${ }^{3}$ Associate Professor, School of Civil, Mining and Environmental Engineering, University of Wollongong, NSW 2522, Australia, Email: msheikh@uow.edu.au
} 
reinforced with steel bars. In addition, the post-peak load-deformation behavior was observed to be more pronounced in specimens reinforced with GSEA sections than in specimens reinforced with steel bars.

Keywords: HSC; Reinforced concrete; Galvanized Steel Equal Angle (GSEA) sections; Concentric axial load; Eccentric axial load; Ductility; $P-M$ interaction.

\section{Introduction}

High strength concrete (HSC) has been widely used in buildings, bridges and other structures due to its advantages over normal strength concrete (NSC). The use of HSC in lower story reinforced concrete (RC) columns of high rise buildings leads to the reduction of column sizes. In addition, strength and durability of RC columns can be increased by using HSC. However, one of the main challenges for the use of HSC in RC columns is the ductility of HSC columns, which is lower than the ductility of NSC columns (Ozbakkaloglu and Saatcioglu 2004; Hadi 2009; Ho et al. 2010).

One of the effective methods for enhancing the ductility and the strength of an RC column is to confine the concrete core of the column adequately with transverse ties or helices. The magnitude of the improvement in the strength and ductility of RC columns is influenced by various parameters including the compressive strength of concrete, volumetric ratio and spacing of transverse reinforcement, and cross-sectional geometry. The efficiency of the confinement provided by the transverse reinforcement decreases with the increase in the compressive strength of concrete (Bjerkeli et al. 1990; Razvi and Saatcioglu 1994; Bayrak and Sheikh 1998). For achieving a similar ductility, HSC columns need to be confined 
46 Khadiranaikar 2012). Circular columns confined with helices exhibit better strength and ductility than the corresponding square columns confined with square ties (Mander et al. 1988a; Mander et al. 1988b; Bjerkeli et al. 1990; Cusson and Paultre 1995).

Longitudinal reinforcement also contributes to the confinement of the concrete core of the columns. A minimum number of longitudinal reinforcement is needed for the stability of steel cages as well as for providing confinement to the transverse expansion of the concrete core. In order to investigate the contribution and the influence of longitudinal reinforcement bars on the ductility of high strength concrete (HSC) columns, a number of studies were carried out in the literature (Yong et al. 1988; Sheikh and Yeh 1990; Awati and Khadiranaikar 2012). It was reported that the distribution of the longitudinal reinforcement influenced the ductility of HSC columns. It was also reported that, for a given area of steel reinforcement, the ductility of the HSC column increases with the increase of the number of longitudinal bars.

This study proposes to use galvanized steel equal angle (GSEA) sections as the longitudinal reinforcement in HSC columns. It is noted that GSEA sections have been extensively used in the construction of steel structures. However, to the knowledge of the authors, no previous study investigated the use of GSEA sections in reinforcing HSC columns. The use of GSEA sections in HSC columns as longitudinal reinforcements may increase the area of the confined concrete core and delay the buckling of longitudinal reinforcement, as a GSEA section has a higher second moment of area than a steel bar for the same cross-sectional area. In this study, the effects of the GSEA sections on the strength and post-peak loaddeformation behavior of square HSC specimens were investigated. The influences of the type of longitudinal reinforcement, the spacing of transverse reinforcement and different loading conditions on the behavior of square HSC specimens have been reported. 


\section{Experimental Program}

72

\section{Specimen Details}

In this study, the test matrix of HSC specimens was developed to examine the influence of the type of longitudinal reinforcement (steel bars or GSEA sections) and the spacing of transverse reinforcement on the behavior of high strength concrete (HSC) specimens under different loading conditions (concentric and eccentric axial loads and four-point loading). The test matrix is shown in Table 1 . Twenty HSC specimens with $210 \mathrm{~mm} \times 210 \mathrm{~mm}$ square cross-section and $800 \mathrm{~mm}$ height were cast and tested. These specimens were divided into five groups. The first group (Group R-S50) was considered as a reference group. The specimens in Group R-S50 were reinforced longitudinally with four N12 bars (deformed steel bars of $12 \mathrm{~mm}$ diameter and $500 \mathrm{MPa}$ nominal yield tensile strength) and transversely reinforced with R10 bars (plain steel bars of $10 \mathrm{~mm}$ diameter and $250 \mathrm{MPa}$ nominal yield tensile strength) at $50 \mathrm{~mm}$ centers. The specimens in the second group (Group A30-S50) were reinforced longitudinally with four A30 GSEA sections and transversely with R10 plain bars at $50 \mathrm{~mm}$ centers. The specimens in the third group (Group A30-S75) were reinforced longitudinally with four A30 GSEA sections and transversely with R10 plain bars at $75 \mathrm{~mm}$ centers. The specimens in the fourth group (Group A40-S50) were reinforced longitudinally with four A40 GSEA sections and transversely with R10 plain bars at $50 \mathrm{~mm}$ centers. The specimens in the fifth group (Group A40-S75) were reinforced longitudinally with four A40 GSEA sections and transversely with R10 plain bars at $75 \mathrm{~mm}$ centers. The A30 GSEA section had a leg width of $29.1 \mathrm{~mm}$ and a thickness of $2.25 \mathrm{~mm}$ and A40 GSEA section had a leg width of $39.3 \mathrm{~mm}$ and a thickness of $3.7 \mathrm{~mm}$. Each group contained four specimens. The first specimen of each group was tested under concentric axial load. The second and third specimens of each group were tested under 25 and $50 \mathrm{~mm}$ eccentric axial load, respectively. 
The last specimen of each group was tested under four-point loading to investigate the flexural behavior.

The specimens were labelled with three parts in Table 1 . The first part refers to the type of longitudinal reinforcement in which R represents N12 steel bars and A30 and A40 refer to GSEA sections. The second part indicates the center-to-center spacing of transverse ties in which S50 and S75 refer to $50 \mathrm{~mm}$ and $75 \mathrm{~mm}$ spacing, respectively. The third part indicates the mode of loading condition in which $\mathrm{C}$ refers concentric axial load, E25 refers to $25 \mathrm{~mm}$ eccentric axial load, E50 refers to $50 \mathrm{~mm}$ eccentric axial load and $\mathrm{F}$ refers to four-point loading. For example, Specimen A30-S75-E25 is reinforced longitudinally with A30 GSEA sections and transversely with R10 plain steel bars at $75 \mathrm{~mm}$ centers, which was tested under $25 \mathrm{~mm}$ eccentric axial load. The details and the designs of each group of specimens are shown in Fig. 1.

\section{Material Properties}

All the concrete specimens were constructed on the same day with a batch of ready-mix concrete provided by a local supplier. The maximum size of the coarse aggregate was $10 \mathrm{~mm}$. The slump of the concrete, tested according to AS 1012.3.1 (2014), was $180 \mathrm{~mm}$, which represented a good workability of the concrete. The average compressive strength of concrete was determined according to AS 1012.9 (2000). Three concrete cylinders with $100 \mathrm{~mm}$ diameter and $200 \mathrm{~mm}$ height were cast and tested for the compressive strength of the concrete. The average compressive strength of concrete on the $28^{\text {th }}$ day was $68.5 \mathrm{MPa}$.

\section{Deformed N12 steel bars were used as longitudinal reinforcement in Group R-S50} specimens. Plain R10 steel bars were used as transverse ties for all specimens. Three samples 
from each of N12 and R10 bars were tested by using the $500 \mathrm{kN}$ Instron universal testing machine according to AS 1391(2007). The average yield tensile strengths were $556 \mathrm{MPa}$ and $323 \mathrm{MPa}$ for N12 and R10 steel bars, respectively.

The galvanized steel equal angle (GSEA) sections (A30 and A40) were supplied by OneSteel (2010). The A30 GSEA had a nominal leg width of $30 \mathrm{~mm}$ and a nominal thickness of 2.5 $\mathrm{mm}$ with a nominal yield tensile strength of $350 \mathrm{MPa}$. The A40 GSEA section had a nominal leg width of $40 \mathrm{~mm}$ and a nominal thickness of $4 \mathrm{~mm}$ with a nominal yield tensile strength of $450 \mathrm{MPa}$. The nominal and measured dimensions and properties of GSEA sections are shown in Table 2. For A30 and A40 GSEA sections, tensile coupons were taken from the flange of the GSEA sections, as shown in Fig. 2. Three coupons from each of A30 and A40 sections were extracted and tested by using the $500 \mathrm{kN}$ Instron universal testing machine according to AS 1391 (2007). The average yield tensile strength for the A30 and A40 GSEA sections were found to be $374 \mathrm{MPa}$ and $473 \mathrm{MPa}$, respectively.

\section{Formwork Setup and Preparation of Specimens}

The formwork used for casting the concrete specimens was fabricated by $17 \mathrm{~mm}$ thick plywood. The combined formwork included five groups of small formwork. Each group was used for casting four specimens. The small formwork was fabricated by two large sheets of plywood $(985 \mathrm{~mm} \times 800 \mathrm{~mm} \times 17 \mathrm{~mm})$ and five small sheets of plywood $(220 \mathrm{~mm} \times 800$ $\mathrm{mm} \times 17 \mathrm{~mm})$. Afterwards, the formwork was prepared by placing the plywood sheets together by screws. Then, pieces of timber were also used vertically and transversely to fix the formwork before pouring the concrete (Fig. 3). At each end, four pieces of Styrofoam (polystyrene) were attached at the corners inside the formwork. Every piece of Styrofoam was $100 \mathrm{~mm}$ long. The Styrofoam was used to create smooth round edges (20 mm radius) at 
each end of the specimen so that the specimen ends could be wrapped with Carbon Fiber

Reinforced Polymer (CFRP) to prevent stress concentrations at the ends during testing. The longitudinal steel bars and GSEA sections were cut into a length of $760 \mathrm{~mm}$ to have a $20 \mathrm{~mm}$ clear cover at the top and bottom of the specimen. For all specimens, the square transverse ties were fabricated from plain R10 steel bars to have $21 \mathrm{~mm}$ clear covers on the sides of the specimen. All transverse ties were bent in the four corners with a radius of $6 \mathrm{~mm}$ to fix the square transverse ties over the GSEA sections. For all specimens, the transverse ties were made with 90-degree hooks around one of the longitudinal reinforcement (steel bars or GSEA sections) and extended with a minimum overlap of $80 \mathrm{~mm}$ at both ends. Afterwards, each tie was welded at three points on the hook corner to ensure adequate confinement by the transverse ties (Fig. 3).

The GSEA sections with smooth surfaces were used as longitudinal reinforcements. Due to the smooth surfaces of GSEA sections, the slippage of the GSEA sections during the test might occur. Therefore, to decrease the effect of slippage in the specimens reinforced with GSEA sections, two small steel bars were welded at the top and bottom of the GSEA sections, as shown in Fig. 3. At first two small steel bars with $8 \mathrm{~mm}$ diameter and $40 \mathrm{~mm}$ length were welded transversely between the ends of GSEA section. Second, two small steel bars with $16 \mathrm{~mm}$ diameter and $70 \mathrm{~mm}$ length were welded at the top and bottom of GSEA sections (Fig. 3). Afterwards, all steel cages were prepared by placing the longitudinal and transverse reinforcement together, as shown in Fig. 3. The concrete was poured into the formwork in three levels. An electric vibrator was used at every level to compact the concrete and remove air bubbles. It is noted that the concrete had good workability (slump=180 mm) with a maximum aggregate size of $10 \mathrm{~mm}$. Hence, no honeycombing was observed in the specimens even for the short steel bars used at the ends of the specimens. After casting, all 
specimens were covered with wet clothes for 28 days. This process was to maintain the specimens under moist conditions. The specimens were removed from the formwork after 14 days, but the specimens remained covered with wet clothes for the next 14 days.

\section{Instrumentation and Testing Procedure}

In this study, the specimens were instrumented externally and internally to monitor the behavior under different loading conditions. The axial deformation for each specimen tested under concentric and eccentric axial compression was monitored by using two linear variable displacement transducers (LVDTs). The LVDTs were attached to the loading plate of the testing machine at two diagonal corners. In addition, the transverse deformation of the specimens tested under eccentric axial load was captured by a laser triangulation, which was placed at the mid-height of the specimens. For specimens under four-point loading, the midspan deflection was captured by a laser triangulation, which was placed vertically underneath the specimens. Prior to pouring the concrete in the formwork, two electrical strain gages were attached at the mid-height on the outside of two opposite longitudinal reinforcement (steel bars and GSEA sections) to monitor the axial stress-axial strain responses of steel bars and GSEA sections. In addition, two electrical strain gages were bonded to the tie bar at the mid-height of the specimens in opposite directions to monitor strains in the transverse direction (Fig. 1). Electrical strain gages, linear variable displacement transducers (LVDTs) and laser triangulation were connected to a data logger and a computer.

A total of twenty HSC specimens were cast and tested in the Structural Engineering Laboratory of the School of Civil, Mining and Environmental Engineering at the University of Wollongong, Australia. The Denison compression testing machine with a load capacity of 
$5000 \mathrm{kN}$ was used to test the specimens. Before testing, the top and bottom surfaces of the specimens tested under concentric and eccentric axial compression were capped with a high strength plaster to provide a uniform load distribution during testing. Afterwards, the specimens were placed vertically between two loading plates of the compression testing machine (Fig. 4). The eccentric axial load was applied to the specimen by an eccentric loading head system manufactured at the University of Wollongong, Australia (Hadi and Widiarsa 2012). The loading head system is shown in Fig. 5. The loading head system consisted of two high strength steel loading heads, which were attached at the top and at the bottom ends of the specimens. A total of five specimens were tested under four-point loading with a clear span of $700 \mathrm{~mm}$, as shown in Fig. 4 (b). The four-point loading system consisted of a set of two steel rigs, which were placed on the bottom and the top of the specimens tested under four-point loading. Typical test setups of the tested specimens under axial load and four-point loading are shown in Fig. 5.

For specimens tested under concentric and eccentric axial load, the test started with an initial force-controlled preloading to about $10 \%$ of the expected maximum axial load of the specimens to regulate minor misalignments between the specimen and the compression testing machine heads. The load was then released to $30 \mathrm{kN}$ at a similar rate. Afterwards, the test resumed under a displacement controlled loading at $0.005 \mathrm{~mm}$ per second until the strength of the specimens dropped to about $40 \%$ of the maximum axial load. For specimens tested under four-point loading, the test was conducted under a displacement control loading at $0.005 \mathrm{~mm}$ per second up to failure. 


\section{Experimental Results and Discussions}

\section{Behavior of Specimens under Concentric Axial Load}

A total of five HSC specimens were tested under concentric axial compression to about $40 \%$ drop in the maximum axial load. The axial load-axial deformation behaviors of all specimens tested under concentric axial load showed similar behavior up to the first peak axial load (Fig. 6). Then the concrete cover spalled off, which led to a drop in the axial load of about $1.1 \%$ to 7.7\% of the first peak axial load. Afterwards, the passive confinement of the concrete core of the specimen was activated and specimens exhibited an increase in the axial load carrying capacity up to the second peak axial load. The second peak axial load were either lower or higher than the first peak axial load depending on the conditions of the confined concrete core (Foster 1999; Hadi et al. 2016). The first crack in Specimen R-S50-C was initiated at the top edge of the specimen, whereas the first crack in Specimens A30-S50-C appeared at the mid-height of the specimen. For Specimens A30-S75-C, A40-S50-C and A40-S75-C, the hairline cracks started at first around the mid-height and then extended near the top one-third height of the specimens (Fig. 7). At the first peak axial load, the strain in the longitudinal N12 steel bars in Specimen R-S50-C was 0.1\%, while the average axial strains in the longitudinal A30 and A40 GSEA sections were $0.08 \%$. The reason for the low axial strain in the longitudinal reinforcement was because the HSC experienced low lateral expansion under axial compression. The low lateral expansion in the HSC is due to higher modulus of elasticity and lower internal micro cracking of the HSC than those of NSC (Cusson and Paultre 1994; Sharma et al. 2005). The failure of the specimens under concentric axial compression was due to the spalling off the concrete cover, followed by outward buckling of the longitudinal steel bars and GSEA sections, as shown in Fig. 8. 
Table 3 presents the experimental results of specimens tested under concentric axial loads in terms of the first and second peak axial loads and the corresponding axial deformations and ductility. The ductility of the tested specimens was determined as a ratio of the deformation at $75 \%$ of the maximum load $\left(\Delta_{0.75}\right)$ in the descending branch of the axial load-axial deformation behavior and the deformation at the yield load $\left(\Delta_{y}\right)$.

$$
\mu=\frac{\Delta_{0.75}}{\Delta_{y}}
$$

where $\Delta_{0.75}$ is the deformation corresponding to the axial load of $75 \%$ of the maximum axial load in the descending branch of the axial load-axial deformation behavior and $\Delta_{y}$ is the deformation corresponding to the yield axial load (Pessiki and Pieroni 1997; Hadi and Widiarsa 2012).

For specimens tested under concentric axial loads, it can be observed that Specimens A30S50-C, A40-S50-C and A40-S75-C had both first and second peak axial loads, whereas Specimens R-S50-C and A30-S75-C had only one peak axial load. This was because the longitudinal GSEA sections were activated and confined the concrete core after cover spalling. For the specimens with the same spacing of transverse ties $(50 \mathrm{~mm})$ and with different types of longitudinal reinforcement (N12 steel bars, A30 and A40 GSEA sections), Specimen A30-S50-C exhibited lower first peak axial load, which was only $6.6 \%$ lower than the first peak axial load of Specimen R-S50-C. This lower peak axial load may be attributed to the fact that N12 steel bars had 49\% higher yield tensile strength than A30 GSEA sections. The second peak axial load of Specimen A30-S50-C was only 1\% lower than the first peak axial load. In addition, the use of the GSEA sections improved the performance of the specimens by enhancing the post-peak axial load-axial deformation behavior, where Specimen A30-S50-C achieved an increase of about $28.6 \%$ in ductility compared to 
Specimen R-S50-C. These observations clearly indicated that by using GSEA sections as the main reinforcement led to a significant increase in the confinement to the concrete core after the concrete cover spalled off. Although steel bars had 18\% higher yield tensile strength than A40 GSEA sections, it was observed that Specimen A40-S50-C achieved about $9.6 \%$ and 25.9\% higher first peak axial load and ductility, respectively, than Specimen R-S50-C. The reason for the higher strength and ductility may be because the A40 GSEA section more effectively confined the concrete core and also the cross-sectional area of the A40 GSEA section was higher than the cross-sectional area of N12 steel bar.

For the specimens reinforced with A30 GSEA sections with different spacings of transverse ties (50 $\mathrm{mm}$ and $75 \mathrm{~mm}$ ), Specimen A30-S50-C exhibited lower first peak axial load, which was only $7.9 \%$ lower than the peak axial load of Specimen A30-S75-C. This lower first peak axial load is due to the development of a plane of weakness between the concrete core and concrete cover in Specimen A30-S50-C. The plane of weakness between concrete core and concrete cover led to the spalling of concrete cover at an early stage of loading (Cusson and Paultre 1994; Razvi and Saatcioglu 1994; Pessiki and Pieroni 1997). However, Specimen A30-S50-C obtained about 29.9\% higher ductility than Specimen A30-S75-C. The reason for this higher ductility was due to the increased confinement for the shorter spacing of transverse ties in Specimen A30-S50-C than the spacing of transverse ties in Specimen A30S75-C.

For the specimens reinforced with A40 GSEA sections with different spacings of transverse ties (50 mm and $75 \mathrm{~mm}$ ), Specimen A40-S50-C showed higher first peak axial load, which was $8.4 \%$ higher than the first peak axial load of Specimen A40-S75-C. The reason is that the decrease in the spacing of transverse ties from $75 \mathrm{~mm}$ to $50 \mathrm{~mm}$ led to an increase in the 
effective confinement area of the concrete core. The second peak axial loads of Specimens A40-S50-C and A40-S75-C were 96.4\% and 98.9\%, respectively, of the corresponding first peak axial loads. This small difference between the first and second peak axial loads of Specimen A40-S50-C and Specimen A40-S75-C indicated that the use of GSEA sections significantly increased the area of confined concrete core. In addition, Specimen A40-S50-C obtained about 5.9\% higher ductility than Specimen A40-S75-C. The increase in ductility was due to the decrease in the spacing of transverse ties from $75 \mathrm{~mm}$ to $50 \mathrm{~mm}$, which led to a more effective confinement of the concrete core.

\section{Behavior of Specimens under Eccentric Axial Load}

From each group, one specimen was tested under $25 \mathrm{~mm}$ eccentric axial load and one specimen was tested under $50 \mathrm{~mm}$ eccentric axial load. All these specimens were tested to about $40 \%$ drop in the maximum axial load. The axial load-axial deformation behavior for eccentrically loaded specimens experienced similar trends up to the maximum axial load. At first, the cracks started on the tension side at the mid-height of the specimens and then extended on the all four sides (Fig. 7). The failure of the specimens tested under eccentric axial loads was initiated by spalling off the concrete cover, followed by buckling of the longitudinal reinforcement and crushing of concrete in the compression zone. It was also observed from the readings of the strain gages attached on the longitudinal reinforcement that all specimens tested under eccentric axial loads were yielded on the compression side. However, the axial strain in Specimen A30-S50-E25 was not measured as the strain gages in Specimen A30-S50-E25 did not function properly during the test.

Table 4 presents the experimental results of specimens tested under $25 \mathrm{~mm}$ eccentric axial load in terms of the yield axial load, the first and second peak axial loads and the 
corresponding axial deformations and ductility. For specimens tested under $25 \mathrm{~mm}$ eccentric axial loads, it can be observed that Specimens A30-S50-E25, A30-S75-E25, A40-S50-E25 and A40-S75-E25 had both first and second peak axial loads, whereas Specimen R-S50-E25 had only one peak axial load (Fig. 9). This observation indicated that the longitudinal GSEA sections were effectively activated to confine the concrete core after the concrete cover spalled off. For the specimens with the same spacing of transverse ties $(50 \mathrm{~mm})$ and with different longitudinal reinforcements (N12 steel bars, A30 and A40 GSEA sections), Specimen A30-S50-E25 exhibited lower first peak axial load, which was only 8.8\% lower than the peak axial load of Specimen R-S50-E25. This may be attributed to the fact that steel bars had $49 \%$ higher yield tensile strength than A30 GSEA sections. However, Specimen A30-S50-E25 obtained about $26.7 \%$ higher ductility than Specimen R-S50-E25 because the bending stiffness of a GSEA section was much greater than the bending stiffness of a steel bar. Although steel bars had 18\% higher yield tensile strength than A40 GSEA sections, it was observed that Specimens A40-S50-E25 obtained 3.3\% and 26.7\% higher first peak axial load and ductility, respectively, than Specimen R-S50-E25. The higher first peak axial load and ductility were because the A40 GSEA section had a much higher bending stiffness than the N12 steel bar.

For the specimens reinforced with A30 GSEA sections with different spacing of transverse misalignments during testing. Therefore, the ductility and strength of Specimen A30-S75-E25 were not further analyzed. 
341 For the specimens reinforced with A40 GSEA sections with different spacings of transverse ties (50 mm and $75 \mathrm{~mm}$ ), Specimen A40-S50-E25 showed higher first peak axial load, which was $8.8 \%$ higher than the first peak axial load of Specimen A40-S75-E25. This may be because of decreased spacing of transverse ties from $75 \mathrm{~mm}$ to $50 \mathrm{~mm}$ improved the confinement to the concrete core. The second peak axial loads of Specimens A40-S50-E25 and A40-S75-E25 were $78.3 \%$ and $82.4 \%$, respectively, of the corresponding first peak axial loads. However, Specimens A40-S50-E25 and A40-S75-E25 showed very similar ductilities.

This may be because the confinement effect from longitudinal GSEA sections decreased under eccentric axial load. Another possible reason was that the use of A40 GSEA sections led to the formation of dense cages, which might have caused to develop a plane of separation between the concrete cover and the concrete core at an early stage of loading.

Table 5 summarizes the experimental results for specimens tested under $50 \mathrm{~mm}$ eccentric axial load in terms of the yield load, the first and second peak axial loads and the corresponding axial deformations and ductility. All these specimens were tested up to about $40 \%$ drop in the maximum axial load. For specimens tested under $50 \mathrm{~mm}$ eccentric axial loads, it can be observed that Specimens R-S50-E50, A30-S50-E50, A40-S50-E50, and A40S75-E50 had both first and second peak axial loads, whereas Specimen A30-S75-E50 had only one peak axial load (Fig. 9). In general, most of the specimens reinforced with GSEA sections had second peak axial loads, which indicated that the longitudinal GSEA sections were effectively activated to confine the concrete core after the concrete cover spalled off. For specimens with the same spacing of transverse ties $(50 \mathrm{~mm})$ and with different longitudinal reinforcements (N12 steel bars, A30 or A40 GSEA sections), Specimen A30S50-E50 obtained 6.4\% lower first peak axial load than Specimen R-S50-E50 (Fig. 10). This lower first peak axial load may be attributed to the fact that N12 steel bars had $49 \%$ higher 
yield tensile strength than A30 GSEA sections. The second peak axial loads of Specimens RS50-E50 and A30-S50-E50 were 70.8\% and 72.2\%, respectively, of the corresponding first peak axial loads. It was observed that Specimen A30-S50-E50 obtained about 8.9\% higher ductility than Specimen R-S50-E50. This slightly higher ductility for GSEA reinforced specimens under $50 \mathrm{~mm}$ eccentric axial loads may be because of higher confinement effectiveness of GSEA sections compared to steel bar specimens under $50 \mathrm{~mm}$ eccentric axial loads. Although steel bars had 18\% higher yield tensile strength than A40 GSEA sections, it was observed that Specimen A40-S50-C obtained 8.8\% higher first peak axial load than Specimen R-S50-E50. The reason for this higher first peak axial load was because the A40 GSEA section had a much higher bending stiffness and a greater cross-sectional area than the N12 steel bar. In addition, Specimen R-S50-E50 exhibited 42.9\% lower ductility than Specimen A40-S50-E50. The reason of the higher strength and ductility may be because the A40 GSEA section had a higher bending stiffness and a greater cross-sectional area than the N12 steel bar.

For the specimens reinforced with A30 GSEA sections with different spacings of transverse ties (50 mm and $75 \mathrm{~mm}$ ), Specimen A30-S50-E50 showed lower first peak axial load, which was $2.9 \%$ lower than the peak axial load of Specimen A30-S75-E50 (Fig. 10). Also, Specimen A30-S50-E50 obtained about 8.2\% higher ductility than Specimen A30-S75-E50.

For the specimens reinforced with A40 GSEA sections with different spacings of transverse ties (50 $\mathrm{mm}$ and $75 \mathrm{~mm}$ ), Specimen A40-S50-E50 showed lower first peak axial load, which was $2.4 \%$ lower than the first peak axial load of Specimen A40-S75-E50. The reason for this may be because the decrease in the spacing of transverse ties from $75 \mathrm{~mm}$ to $50 \mathrm{~mm}$ resulted in increased amount of steel reinforcement, which led to the development of a plane of 
separation between the concrete cover and the concrete core at an early stage of loading. The second peak axial loads of Specimens A40-S50-E50 and A40-S75-E50 were $77.7 \%$ and $74.6 \%$ respectively, of the corresponding first peak axial loads. Also, Specimen A40-S50E50 showed 25.0\% higher ductility than Specimen A40-S75-E50.

\section{Behavior of Specimens under Four-Point Loading}

One specimen from each group was tested under four-point loading. All specimens were tested to failure. For uniformity and consistency, the specimens tested under four-point loading were kept the same as the other specimens tested under concentric and eccentric axial loads. As the load was applied, tension cracks started at midspan on the bottom side (tension surface) of the specimen. As the load increased, cracks became wider and extended to the side of the whole specimen, as shown in Fig. 11. The failure of all specimens tested under four-point loading was due to the rupture of longitudinal reinforcement (steel bars and GSEA sections) on the tension sides.

Fig. 12 shows the load-midspan deflection behavior of the specimens tested under four-point loading. It can be observed that all specimens showed similar behavior in the elastic region. After the load reached the maximum value, a sudden decrease in the load occurred. The specimens still resisted the applied load with increasing displacement, while the failure of the specimen occurred by yielding and then rupture of the longitudinal tensile reinforcement (steel bars and GSEA sections). The typical failure occurred for all tested specimens by the rupture of steel reinforcement (steel bars and GSEA sections) on the tension side. It can be also observed from Fig. 12 that all specimens reinforced with GSEA sections exhibited better performances in terms of post-peak load-midspan deflection behavior and load carrying capacity compared to the R-S50-F specimen. 
416 Table 6 summarizes the experimental results of the tested specimens under four-point loading 417 in terms of the yield load and maximum load, corresponding midspan deflections and 418 ductility. For the specimens with the same spacing of transverse ties $(50 \mathrm{~mm})$ and with 419 different longitudinal reinforcements (N12 steel bars, A30 and A40 GSEA sections), it can be 420 observed that although steel bars had $49 \%$ higher yield tensile strength than A30 GSEA sections, Specimens A30-S50-F exhibited 6.3\% higher maximum load than Specimen R-S50F. It can also be observed that Specimen A30-S50-F achieved about 35.3\% higher ductility than Specimen R-S50-F. The higher maximum load and ductility was because, for a similar longitudinal reinforcement area, the A30 GSEA section had a higher bending stiffness than the N12 steel bar. Although steel bars had 18\% higher yield tensile strength than A40 GSEA sections, the maximum load of Specimen A40-S50-F was about 100\% higher than the maximum load of Specimen R-S50-F and the ductility of Specimen A40-S50-F was about $8.8 \%$ higher than the ductility of Specimen R-S50-F. The increases in the maximum load and ductility were because the A40 GSEA section had a much higher bending stiffness than the N12 steel bars. Another reason might be that the cross-sectional area of the A40 GSEA section was greater than the cross-sectional area of the N12 steel bar, which provided increased bond effect between the longitudinal reinforcement and surrounding concrete.

For the specimens reinforced with A30 GSEA sections and different spacings of transverse ties $(50 \mathrm{~mm}$ and $75 \mathrm{~mm})$, it can be observed that Specimens A30-S50-F and Specimen A30S75-F exhibited similar maximum loads. It can also be observed that Specimens A30-S50-F achieved about $21.1 \%$ higher ductility than Specimen A30-S75-F. This may be because the smaller tie spacing of $50 \mathrm{~mm}$ led to better control of the shear crack width than the wider tie spacing of $75 \mathrm{~mm}$. 
441 For the specimens reinforced with A40 GSEA sections with different spacings of transverse 442 ties (50 mm and $75 \mathrm{~mm}$ ), Specimens A40-S50-F and A40-S75-F exhibited similar maximum 443 loads. This was because the confinement effect due to lateral reinforcement in the beams is 444 not generally significant at the peak load. Similar observations were reported in Rashid and 445 Mansur (2005) and in Kwan et al. (2006). However, Specimens A40-S50-F showed about 8.1\% lower ductility than Specimen A40-S75-F. The reason for the decrease in the ductility may be because the Specimen A40-S50-F with closer transverse tie spacing $(50 \mathrm{~mm})$ had a higher amount of transverse steel reinforcement than A40-S75-F with wider transverse tie spacing $(75 \mathrm{~mm})$, which led to the development of a plane of separation between the concrete cover and the concrete core in the compression zone at an early stage of loading.

Axial Load-Bending Moment (P-M) Interactions

453

The experimental axial load-bending moment $(P-M)$ interactions were constructed using pure concentric axial load, combined axial load and bending moment $(25 \mathrm{~mm}$ and $50 \mathrm{~mm}$ eccentric axial loads) and pure bending moment (four-point loading). The bending moment capacity of the specimens under eccentric axial load was calculated using Eq. (2):

$$
M=P(e+\Delta)
$$

where $P$ is the maximum axial load, $e$ is the axial load eccentricity and $\Delta$ is the lateral deformation at the maximum axial load. The pure bending moment capacity at the mid-height of the specimens tested under four-point loading was calculated using Eq. (3):

$$
M=\frac{P L}{6}
$$

where $P$ is the maximum load under four-point loading and $L$ is the clear span of the tested specimen, as shown in Fig. 4 (b). 
463 The experimental axial load-bending moment $(P-M)$ interactions of Groups R-S50, A30-S50, 464 A30-S75, A40-S50 and A40-S75 specimens are shown in Fig. 13. Also, the experimental bending moment capacities of the tested specimens are reported in Table 7 . It can be seen that GSEA reinforced A30-S50 and A30-S75 specimens (except A30-S75-C) showed slightly

467 lower peak axial loads than the steel bar reinforced R-S50 specimens. This is because steel bars had 49\% higher yield tensile strength than A30 GSEA sections. However, it can be observed that all specimens reinforced with GSEA sections exhibited higher bending moments than specimens reinforced with steel bars. Although steel bars had $18 \%$ higher yield tensile strength than A40 GSEA sections, it can be observed that all the specimens (except A40-S75-E25) in the Groups A40-S50 and A40-S75 exhibited higher peak axial loads and bending moments than the steel bar reinforced specimens in Group R-S50. The use of longitudinal GSEA sections resulted in enhancing the performance of specimens significantly under four-point loading. This is because the bending stiffness of a GSEA section is much higher than the bending stiffness of steel bar with the similar cross-sectional area.

\section{Analytical Axial Load-Bending Moment (P-M) Interactions}

In this study, analytical axial load-bending moment $(P-M)$ interactions were constructed (Fig.

14) to check whether the available analytical tools can predict the axial load-bending moment $(P-M)$ interactions of HSC columns reinforced with GSEA sections. The $P-M$ interactions were drawn based on the principles of strain compatibility and force equilibrium. In this study, the $P-M$ interaction diagrams of the tested specimens were drawn with four points (Fig. 15). The first point (i) on the $P-M$ interaction diagram represents pure axial compression. The second (ii) and third (iii) points on $P-M$ interaction diagram represent 25 
interaction diagram represents pure bending moment (four-point loading). The axial load capacity of the specimen under concentric axial load was calculated using Eq. (4):

$$
P_{o}=\alpha_{1} f_{c}^{\prime}\left(A_{g}-A_{s}\right)+f_{y} A_{s}
$$

489

490

491

492

$$
\alpha_{1}=1-0.003 f_{c}^{\prime}
$$$$
0.72 \leq \alpha_{1} \leq 0.85
$$

493 The $\alpha_{1}$ is dependent on the compressive strength of concrete (in this study, $\alpha_{1}=0.794$ ).

494 In order to use strain compatibility and force equilibrium to construct the analytical $P-M$ 495 interaction diagrams of the RC columns, the following assumptions were made

1. The plane section remains plane after deformation and perpendicular to the neutral axis.

497 Also, the distribution of concrete strain is assumed to be linear across the height of the 498 section.

499 2. A perfect bond exists between concrete and steel reinforcement (steel bars and SEA 500 sections).

5013 . The tensile strength of concrete is negligible.

502 4. Steel reinforcement (steel bars and GSEA sections) behave as elastic-perfectly plastic.

503 5. The confinement effect by the transverse reinforcement (ties) is neglected because the 504 transverse reinforcement was assumed to increase only the ductility (Kim et al. 2011).

505 The compressive force $C_{c}$ in the concrete is obtained by the stress block method (AS 3600 506 2009).

$$
C_{c}=\alpha_{2} f_{c}^{\prime} b \gamma d_{n}
$$

507 The strain in the compressive steel reinforcement was calculated as: 


$$
\varepsilon_{s c}=\varepsilon_{c u} \frac{\left(d_{n}-d_{s c}\right)}{d_{n}}
$$

508 The stress in the compressive steel reinforcement was calculated as:

$$
\sigma_{s c}=E_{s} \varepsilon_{s c} \quad \varepsilon_{s c}<\varepsilon_{s y}
$$

509 Or

$$
\sigma_{s c}=f_{s y} \quad \varepsilon_{s c} \geq \varepsilon_{s y}
$$

510 Therefore, the force in the compressive steel reinforcement was calculated as:

$$
C_{s}=\sigma_{s c} A_{s c}
$$

511 Similarly, the stress in the tensile steel reinforcement was calculated as:

$$
\sigma_{s t}=E_{s} \varepsilon_{s t} \quad \varepsilon_{s t}<\varepsilon_{s y}
$$

512 Or

$$
\sigma_{s t}=f_{s y} \quad \varepsilon_{s t} \geq \varepsilon_{s y}
$$

513 where $f_{s y}, \varepsilon_{s y}$ and $E_{s}$ are the yield tensile stress, corresponding yield tensile strain and the 514 modulus of elasticity of steel reinforcement. The tensile force in the tensile reinforcement can 515 be calculated as:

$$
T_{s}=\sigma_{s t} A_{s t}
$$

516 The axial load $\left(P_{u}\right)$ and the bending moment $\left(M_{u}\right)$ capacities were calculated using Eq. (14) 517 and (15), respectively:

$$
\begin{gathered}
P_{u}=C_{c}+C_{s}-T_{s} \\
M_{u}=C_{c}\left(\frac{h}{2}-\frac{\gamma d_{n}}{2}\right)+C_{s}\left(\frac{h}{2}-d_{s c}\right)+T_{s}\left(d-\frac{h}{2}\right)
\end{gathered}
$$

518 where $C_{c}$ and $C_{s}$ are the compressive force in concrete and longitudinal reinforcement, 519 respectively, $T_{s}$ is the tensile force in the tension reinforcement and $h$ is the total high of the 520 cross-section of the specimen. The factors $\alpha_{2}$ and $\gamma$ were calculated based on the 521 recommendations in AS 3600 (2009) $\left(\alpha_{2}=1-0.003 f_{c}^{\prime}\right.$ within the limit $\left.0.67 \leq \gamma \leq 0.85\right)$ 
and $\left(\gamma=1.05-0.007 f_{c}^{\prime}\right.$ within the limit $\left.0.67 \leq \gamma \leq 0.85\right)$. The $d_{s c}$ and $d$ are distances from the extreme compression concrete fiber to the centroids of compressive longitudinal

524 reinforcement and tensile longitudinal reinforcement, respectively. The $d_{n}$ is the depth of the neutral axis.

Experimental and analytical axial load-bending moment $(P-M)$ interactions of all tested specimens are shown in Fig. 16 (a-e). The experimental and analytical $P-M$ interactions of specimens in Group R-S50 are shown in Fig. 16 (a). The experimental and analytical $P-M$ interactions of specimens in Groups A30-S50 and A30-S75 are shown in Fig. 16 (b) and (c), respectively. The experimental and analytical $P-M$ interactions of specimens in Groups A40S50 and A40-S75 are shown in Fig. 16 (d) and (e), respectively. Also, the analytical axial loads and bending moment capacities of the tested specimens are reported in Table 7. It can be observed that the analytical axial load-bending moment interactions match very well with the experimental axial load-bending moment interactions of R-S50 (Fig. 16 (a)). Also, it can be observed that analytical axial loads are within $93 \%-104 \%$ of experimental axial loads for specimens reinforced with GSEA sections tested under concentric axial load. Analytical axial loads are within $105 \%-114 \%$ and $102 \%-106 \%$ of experimental axial loads for specimens reinforced with GSEA sections tested under $25 \mathrm{~mm}$ and $50 \mathrm{~mm}$ eccentric axial loads, respectively. Analytical bending moments are within $98 \%-106 \%$ and $97 \%-105 \%$ of experimental bending moments for specimens reinforced with GSEA sections tested under 25 $\mathrm{mm}$ and $50 \mathrm{~mm}$ eccentric axial loads, respectively. However, the analytical bending moments are within $63 \%-71 \%$ of experimental bending moments for specimens reinforced with GSEA sections tested under four-point loading. The reason for the large differences between experimental and analytical bending moments under four-point loading was due to small shear span to depth ratio of the tested specimens. Another possible reason might be that the 
analytical method did not adequately take into account the bending stiffness of the

547 longitudinal reinforcement.

548

\section{Conclusions}

550 In this study, a total of 20 square HSC specimens were tested under concentric and eccentric

551 axial loads and four-point loadings to explore the behavior of HSC specimens reinforced 552 longitudinally with GSEA sections. The main parameters examined included: the type of 553 longitudinal reinforcement (steel bars and GSEA sections), the spacing of transverse ties and 554 different loading conditions. Based on the experimental results, the following conclusions can 555 be drawn:

- In general, the specimens reinforced with GSEA sections under concentric and eccentric 557 axial loads experienced two peak axial loads while the specimen reinforced with steel bars 558 experienced one peak axial load. This indicates that the longitudinal GSEA sections 559 positively influenced the confinement of the concrete core after the spalling of concrete 560 cover.

- Specimens A30-S50-C, A30-S50-E25 and A30-S50-E50 carried about 6.6\%, 8.8\% and 6.4\% lower maximum axial load than Specimens R-S50-C, R-S50-E25 and R-S50-E50, respectively. These slightly lower maximum axial loads were mainly because the A30 564 GSEA sections had $49 \%$ lower yield tensile strength than steel bars. In other words, the force contribution of A30 GSEA sections was lower than the force contributions of N12 steel bars by about 27\%. However, the ductilities of Specimens A30-S50-C, A30-S50-E25 and A30-S50-E50 were $28.6 \%, 26.7 \%$ and $8.9 \%$, respectively, higher than the ductility of the Specimens R-S50-C, R-S50-E25 and R-S50-E50. This indicates that the A30 GSEA section effectively confined the concrete core of the tested specimens, as the ductility of the 
specimens reinforced with A30 GSEA sections was higher than the ductility of the reference

571 specimens.

572 - Specimen A30-S75-E50 obtained only 3.3\% lower maximum axial load than the reference

573 Specimen R-S50-E50. It is noted that the transverse tie spacing of Specimen A30-S75-E50

574 was $75 \mathrm{~mm}$ and transverse tie spacing of Specimen R-S50-E50 was $50 \mathrm{~mm}$. Under 575 concentric axial load, Specimens R-S50-C and A30-S75-C achieved similar maximum axial 576 loads

577 - For all loading conditions, specimens of Group A40-S50 exhibited higher maximum axial 578 load and higher ductility than specimens of the reference Group R-S50 because of the more 579 effective confinement provided by A40 GSEA sections than steel bars. Another possible 580 reason is that A40 GSEA sections had higher cross-sectional areas than N12 steel bars.

- The maximum axial load of Specimens A40-S75-C and A40-S75-E50 were higher than the 582 maximum axial load of Specimens R-S75-C and R-S75-E50, respectively. However, the 583 maximum axial load of Specimen R-S50-E25 was slightly higher than the maximum axial load of Specimen A40-S75-E25. It is noted that the transverse tie spacing of Specimen A40S75-E25 was $75 \mathrm{~mm}$ and the transverse tie spacing of Specimen R-S50-E25 was $50 \mathrm{~mm}$. All the specimens of Group A40-S75 achieved higher ductility than the specimens in the 587 reference Group R-S50.

- All specimens reinforced with GSEA sections (A30-S50-F, A30-S75-F, A40-S50-F and 589 A40-S75-F) exhibited higher maximum loads and significantly higher ductility than the specimen reinforced with steel bars (R-S50-F). This is because the GSEA sections had 591 higher bending stiffness than the N12 steel bars.

592 - The analytical axial load-bending moment interactions are in good agreement with the 593 experimental results, particularly for specimens tested under concentric and eccentric axial loads. 
Finally, the use of GSEA sections as longitudinal reinforcements can be recommended to improve the performance of concrete members.

\section{Acknowledgments}

The authors would like to thank the University of Wollongong, Australia and technical officers at the High Bay Laboratory, especially Mr. Alan Grant, Mr. Fernando Escribano, Mr. Duncan Best, Mr. Ritchie Mclean and Mr. Richard Gasser for their help in the experimental program of this study. Also, the second author would like to thank the Higher Committee for Education Development in Iraq and the University of Babylon for the support of his Ph.D. scholarship.

\section{References}

AS (Australian Standard ). (2000). "Methods of testing concrete - Method 9: Determination of the compressive strength of concrete specimens." AS 1012.9, Sydney, Australia.

AS (Australian Standard). (2007). "Metallic materials tensile testing at ambient temperature." AS 1391-2007, Sydney, Australia.

AS (Australian Standard). (2009). "Concrete structures." AS 3600-2009, Sydney, Australia.

AS (Australian Standard). (2014). "Methods of testing concrete-Method 3.1: determination of properties related to the consistency of concrete-Slump test." AS 1012.3.1, Sydney, Australia.

Awati, M., and Khadiranaikar, R. (2012). "Behavior of concentrically loaded high performance concrete tied columns." Engineering Structures. 37, 76-87.

Bayrak, O., and Sheikh, S. A. (1998). "Confinement reinforcement design considerations for ductile HSC columns." Journal of Structural Engineering. 124(9), 999-1010.

Bjerkeli, L., Tomaszewicz, A., and Jensen, J. (1990). "Deformation properties and ductility of high-strength concrete." ACI Special Publication. 121, 215-238.

Cusson, D., and Paultre, P. (1994). "High-strength concrete columns confined by rectangular ties." Journal of Structural Engineering. 120(3), 783-804. 
Cusson, D., and Paultre, P. (1995). "Stress-strain model for confined high-strength concrete." Journal of Structural Engineering. 121(3), 468-477.

Foster, S. J. (1999). "Design and detailing of high strength concrete columns.", Sydney, University of New South Wales, School of Civil Engineering.

Hadi, M. (2009). "Reinforcing concrete columns with steel fibres." Asian Journal of Civil Engineering (Building and Housing). 10(1), 79-95.

Hadi, M. N., Karim, H., and Sheikh, M. N. (2016). "Experimental Investigations on Circular Concrete Columns Reinforced with GFRP Bars and Helices under Different Loading Conditions." Journal of Composites for Construction. 20(4), 04016009.

Hadi, M. N., and Widiarsa, I. B. R. (2012). "Axial and flexural performance of square RC columns wrapped with CFRP under eccentric loading." Journal of Composites for Construction. 16(6), 640-649.

Ho, J., Lam, J., and Kwan, A. (2010). "Effectiveness of adding confinement for ductility improvement of high-strength concrete columns." Engineering Structures. 32(3), 714725.

Kim, C. S., Park, H. G., Chung, K. S., and Choi, I. R. (2011). "Eccentric axial load testing for concrete-encased steel columns using $800 \mathrm{MPa}$ steel and $100 \mathrm{MPa}$ concrete." Journal of Structural Engineering. 138(8), 1019-1031.

Kwan, A., Chau, S., and Au, F. (2006). "Improving flexural ductility of high-strength concrete beams." Structures and Buildings. 159(6), 339-347.

Mander, J., Priestley, M., and Park, R. (1988a). "Observed stress-strain behavior of confined concrete." Journal of Structural Engineering. 114(8), 1827-1849.

Mander, J. B., Priestley, M. J., and Park, R. (1988b). "Theoretical stress-strain model for confined concrete." Journal of Structural Engineering. 114(8), 1804-1826.

Mendis, P., Kovacic, D., and Setunge, S. (2000). "Basis for the design of lateral reinforcement for high-strength concrete columns." Structural Engineering and Mechanics. 9(6), 589-600.

OneSteel. (2010). "Know your steel: steel reference guide.", Wollongong, NSW, Australia [www.onesteel.com],

Ozbakkaloglu, T., and Saatcioglu, M. (2004). "Rectangular stress block for high-strength concrete." ACI Structural Journal. 101(4), 475-483.

Pessiki, S., and Pieroni, A. (1997). "Axial load behavior of large-scale spirally-reinforced high-strength concrete columns." ACI Structural Journal., 94(3), 304-313.

Rashid, M., and Mansur, M. (2005). "Reinforced high-strength concrete beams in flexure." ACI Structural Journal. 102(3), 462-471. 
Razvi, S. R., and Saatcioglu, M. (1994). "Strength and deformability of confined highstrength concrete columns." Structural Journal. 91(6), 678-687.

Sharma, U. K., Bhargava, P., and Kaushik, S. (2005). "Behavior of confined high strength concrete columns under axial compression." Journal of Advanced Concrete Technology. 3(2), 267-281.

Sheikh, S. A., and Yeh, C. C. (1990). "Tied concrete columns under axial load and flexure." Journal of Structural Engineering. 116(10), 2780-2800.

Soliman, M., and Yu, C. (1967). "The flexural stress-strain relationship of concrete confined by rectangular transverse reinforcement." Magazine of Concrete Research. 19(61), 223-238.

Yong, Y. K., Nour, M. G., and Nawy, E. G. (1988). "Behavior of laterally confined highstrength concrete under axial loads." Journal of Structural Engineering. 114(2), 332351. 


\section{List of Tables}

Table 1. Test Matrix

Table 2. Dimensions and Properties of Galvanized Steel Equal Angle (GSEA) Sections

Table 3. Experimental Results of the Tested Specimens under Concentric Axial Loads

Table 4. Experimental Results of the Tested Specimens under $25 \mathrm{~mm}$ Eccentric Axial Loads

Table 5. Experimental Results of the Tested Specimens under $50 \mathrm{~mm}$ Eccentric Axial Loads

Table 6. Experimental Results of the Tested Specimens under Four-point Loading

Table 7. Experimental and Analytical Bending Moment Capacity of the Tested Specimens 


\section{List of Figures}

Fig. 1. Dimension and reinforcement arrangements of the test specimens

Fig. 2. Details of tensile coupon specimens of galvanized steel equal angle (GSEA) section:

(a) A30; (b) A40

Fig. 3. Overview of steel cages and formwork for tested specimens

Fig. 4. Testing of specimens: (a) Specimen under eccentric axial load; (b) Specimen under four-point loading

Fig. 5. Typical testing setup: (a) Specimen under axial compression; (b) Loading head and eccentric load system; (c) Specimen under four-point loading

Fig. 6. Axial load-axial deformation response of specimens tested under concentric axial load

Fig. 7. Failure modes of the tested specimens under axial compression

Fig. 8. Close-up view of the typical failure under concentric axial load: (a) R-S50-C; (b) A40-S75-C

Fig. 9. Axial load-axial deformation and axial load-lateral deformation response of specimens tested under $25 \mathrm{~mm}$ eccentric axial load

Fig. 10. Axial load-axial deformation and axial load-lateral deformation response of specimens tested under $50 \mathrm{~mm}$ eccentric axial load

Fig. 11. Failure modes of the tested specimens under four-point loading

Fig. 12. Load-midspan deflection behavior of specimens tested under four-point loading

Fig. 13. Experimental axial load-bending moment $(P-M)$ interactions of tested specimens

Fig. 14. Stress-strain distribution and force equilibrium of specimens under eccentric axial compression

Fig. 15. $P-M$ interaction diagram 
Fig. 16. Experimental and analytical axial load-bending moment $(P-M)$ interactions of tested specimens 
Table 1. Test Matrix

\begin{tabular}{|c|c|c|c|c|c|c|c|c|c|c|}
\hline \multirow{3}{*}{ Group } & \multirow{3}{*}{$\begin{array}{l}\text { Specimen } \\
\text { Labels }\end{array}$} & \multicolumn{6}{|c|}{ Longitudinal Reinforcement } & \multirow{2}{*}{\multicolumn{2}{|c|}{$\begin{array}{c}\text { Transverse } \\
\text { Reinforcement }\end{array}$}} & \multirow{3}{*}{$\begin{array}{c}\text { Load } \\
\text { eccentricity }\end{array}$} \\
\hline & & \multirow{2}{*}{$\begin{array}{c}\text { Reinforcement } \\
\text { Type }\end{array}$} & \multirow{2}{*}{ Number } & \multicolumn{2}{|c|}{ Bar } & \multicolumn{2}{|c|}{$\begin{array}{c}\text { Galvanized Steel } \\
\text { Equal Angle (GSEA) } \\
\text { Section }\end{array}$} & & & \\
\hline & & & & $\begin{array}{l}\text { Diameter } \\
(\mathrm{mm})\end{array}$ & $\begin{array}{l}\rho_{b} \\
\%\end{array}$ & $\begin{array}{l}\text { Dimension } \\
(\mathrm{mm})\end{array}$ & $\underset{\%}{\rho_{S E A}}$ & $\begin{array}{l}\text { Diameter } \\
(\mathrm{mm})\end{array}$ & $\begin{array}{c}\text { Spacing } \\
(\mathrm{mm})\end{array}$ & \\
\hline \multirow{4}{*}{ R-S50 } & R-S50-C & \multirow{4}{*}{ Steel Bar } & \multirow{4}{*}{4} & \multirow{4}{*}{12} & \multirow{4}{*}{1.03} & \multirow{4}{*}{\multicolumn{2}{|c|}{-}} & \multirow{4}{*}{10} & \multirow{4}{*}{50} & 0 \\
\hline & R-S50-E25 & & & & & & & & & $25 \mathrm{~mm}$ \\
\hline & R-S50-E50 & & & & & & & & & $50 \mathrm{~mm}$ \\
\hline & R-S50-F & & & & & & & & & Flexural \\
\hline \multirow{4}{*}{ A30-S50 } & A30-S50-C & & \multirow{4}{*}{4} & \multirow{4}{*}{-} & & \multirow{4}{*}{$29.1 \times 2.25$} & \multirow{4}{*}{1.11} & \multirow{4}{*}{10} & \multirow{4}{*}{50} & 0 \\
\hline & A30-S50-E25 & & & & & & & & & $25 \mathrm{~mm}$ \\
\hline & A30-S50-E50 & & & & & & & & & $50 \mathrm{~mm}$ \\
\hline & A30-S50-F & & & & & & & & & Flexural \\
\hline \multirow{4}{*}{ A $30-S 75$} & A30-S75-C & & \multirow{5}{*}{4} & \multirow{4}{*}{ - } & & \multirow{4}{*}{$29.1 \times 2.25$} & \multirow{5}{*}{1.11} & \multirow{4}{*}{10} & \multirow{4}{*}{75} & 0 \\
\hline & A30-S75-E25 & & & & & & & & & $25 \mathrm{~mm}$ \\
\hline & A30-S75-E50 & Galvanized Steel & & & & & & & & $50 \mathrm{~mm}$ \\
\hline & A30-S75-F & Equal Angle & & & & & & & & Flexural \\
\hline \multirow{4}{*}{ A40-S50 } & A40-S50-C & (GSEA) Section & & & & & & & & 0 \\
\hline & A40-S50-E25 & & 1 & & & $302 \times 27$ & 242 & 10 & 50 & $25 \mathrm{~mm}$ \\
\hline & A40-S50-E50 & & 4 & - & & $39.3 \times 3.1$ & 2.43 & 10 & 50 & $50 \mathrm{~mm}$ \\
\hline & A40-S50-F & & & & & & & & & Flexural \\
\hline & A40-S75-C & & & & & & & & & 0 \\
\hline A 40-S75 & A40-S75-E25 & & 4 & - & & $393 \times 37$ & 243 & 10 & 75 & $25 \mathrm{~mm}$ \\
\hline & A40-S75-E50 & & & & & 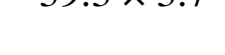 & & & & $50 \mathrm{~mm}$ \\
\hline & A40-S75-F & & & & & & & & & Flexural \\
\hline
\end{tabular}

Note: $\rho_{b}$ represents volumetric ratio of longitudinal reinforcement bars and $\rho_{S E A}$ represents volumetric ratio of longitudinal GSEA sections 
Table 2. Dimensions and Properties of Galvanized Steel Equal Angle (GSEA) Sections

\begin{tabular}{cccccc}
\hline \multirow{2}{*}{\begin{tabular}{c} 
Galvanized \\
Equal Angle \\
(GSEA) \\
\cline { 2 - 6 } Section
\end{tabular}} & $\begin{array}{c}\text { Leg } \\
\text { Width } \\
(\mathrm{mm})\end{array}$ & $\begin{array}{c}\text { Thickness } \\
(\mathrm{mm})\end{array}$ & $\begin{array}{c}\text { Area } \\
\left(\mathrm{mm}^{2}\right)\end{array}$ & $\begin{array}{r}\text { Yensile } \\
\text { Strength } \\
(\mathrm{MPa})\end{array}$ & $\begin{array}{c}\text { Modulus of } \\
\text { Elasticity } \\
(\mathrm{GPa})\end{array}$ \\
\hline A30 & 30 & 2.5 & 132 & 350 & 200 \\
A40 & 40 & 4.0 & 280 & 450 & 200 \\
\cline { 2 - 6 } & & & Measured & \\
A30 & 29.1 & 2.25 & 122.6 & 374 & 208 \\
A40 & 39.3 & 3.70 & 268.3 & 473 & 205 \\
\hline
\end{tabular}


Table 3. Experimental Results of the Tested Specimens under Concentric Axial Loads

\begin{tabular}{|c|c|c|c|c|c|c|c|c|}
\hline \multirow[b]{2}{*}{ Specimen } & \multirow[b]{2}{*}{$\begin{array}{c}\text { Yield } \\
\text { load } \\
P_{y} \\
(\mathrm{kN})\end{array}$} & \multirow{2}{*}{$\begin{array}{c}\text { Axial } \\
\text { deformation } \\
\Delta_{y} \\
\text { at }\left(P_{y}\right) \\
(\mathrm{mm})\end{array}$} & \multicolumn{2}{|c|}{ First Peak } & \multicolumn{2}{|c|}{ Second Peak } & \multirow[b]{2}{*}{$\begin{array}{l}\text { Deformation } \\
\Delta_{0.75}{ }^{\mathrm{a}} \\
(\mathrm{mm})\end{array}$} & \multirow[b]{2}{*}{ Ductility ${ }^{b}$} \\
\hline & & & $\begin{array}{l}\text { Axial } \\
\text { load } \\
(\mathrm{kN})\end{array}$ & $\begin{array}{c}\text { Axial } \\
\text { deformation } \\
(\mathrm{mm})\end{array}$ & $\begin{array}{l}\text { Axial } \\
\text { load } \\
(\mathrm{kN})\end{array}$ & $\begin{array}{c}\text { Axial } \\
\text { deformation } \\
(\mathrm{mm})\end{array}$ & & \\
\hline R-S50-C & 2618 & 2.6 & 2716 & 2.8 & - & - & 3.8 & 1.4 \\
\hline A30-S50-C & 2509 & 2.5 & 2548 & 2.6 & 2524 & 2.8 & 4.5 & 1.8 \\
\hline A30-S75-C & 2595 & 2.3 & 2749 & 2.6 & - & - & 3.2 & 1.4 \\
\hline A40-S50-C & 2874 & 2.5 & 2977 & 2.7 & 2873 & 3 & 4.4 & 1.8 \\
\hline A40-S75-C & 2634 & 2.4 & 2747 & 2.6 & 2716 & 2.7 & 4.1 & 1.7 \\
\hline
\end{tabular}

Note: ${ }^{\mathrm{a}} \Delta_{0.75}$ represents the deformation corresponding axial load at $75 \%$ of the maximum axial load in the descending branch of the axial loadaxial deformation behavior

${ }^{\mathrm{b}}$ Calculated using Eq. (1). 
Table 4. Experimental Results of the Tested Specimens under $25 \mathrm{~mm}$ Eccentric Axial Loads

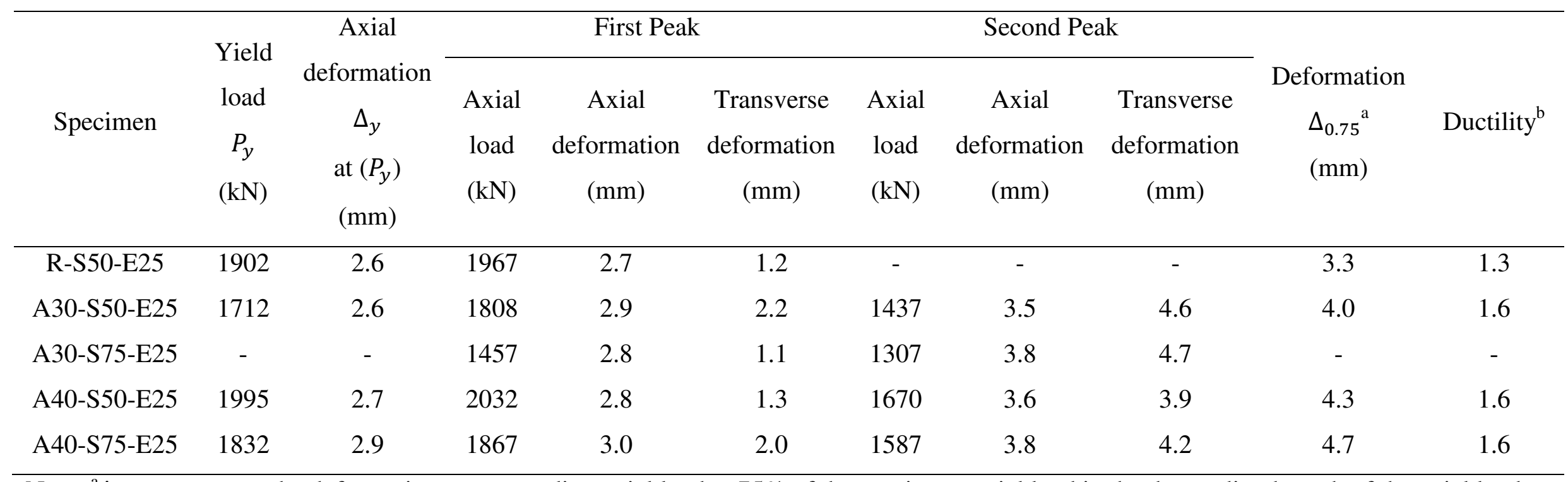

Note: ${ }^{a} \Delta_{0.75}$ represents the deformation corresponding axial load at $75 \%$ of the maximum axial load in the descending branch of the axial loadaxial deformation behavior

${ }^{\mathrm{b}}$ Calculated using Eq. (1). 
Table 5. Experimental Results of the Tested Specimens under $50 \mathrm{~mm}$ Eccentric Axial Loads

\begin{tabular}{|c|c|c|c|c|c|c|c|c|c|c|}
\hline \multirow[b]{2}{*}{ Specimen } & \multirow{2}{*}{$\begin{array}{c}\text { Yield } \\
\text { load } \\
P_{y} \\
(\mathrm{kN})\end{array}$} & \multirow{2}{*}{$\begin{array}{c}\text { Axial } \\
\text { deformation } \\
\Delta_{y} \text { at }\left(P_{y}\right) \\
(\mathrm{mm})\end{array}$} & \multicolumn{3}{|c|}{ First Peak } & \multicolumn{3}{|c|}{ Second Peak } & \multirow[b]{2}{*}{$\begin{array}{c}\text { Deformation } \\
\Delta_{0.75}{ }^{\mathrm{a}} \\
(\mathrm{mm})\end{array}$} & \multirow[b]{2}{*}{ Ductility $^{\mathrm{b}}$} \\
\hline & & & $\begin{array}{l}\text { Axial } \\
\text { load } \\
(\mathrm{kN})\end{array}$ & $\begin{array}{c}\text { Axial } \\
\text { deformation } \\
(\mathrm{mm})\end{array}$ & $\begin{array}{c}\text { Transverse } \\
\text { deformation } \\
(\mathrm{mm})\end{array}$ & $\begin{array}{l}\text { Axial } \\
\text { load } \\
(\mathrm{kN})\end{array}$ & $\begin{array}{c}\text { Axial } \\
\text { deformation } \\
(\mathrm{mm})\end{array}$ & $\begin{array}{c}\text { Transverse } \\
\text { deformation } \\
(\mathrm{mm})\end{array}$ & & \\
\hline R-S50-E50 & 1323 & 2.6 & 1340 & 2.7 & 1.9 & 1037 & 3.4 & 4.5 & 3.7 & 1.4 \\
\hline A30-S50-E50 & 1227 & 2.4 & 1260 & 2.5 & 1.1 & 986 & 3.2 & 3.2 & 3.6 & 1.5 \\
\hline A30-S75-E50 & 1260 & 2.3 & 1297 & 2.5 & 3.0 & - & - & - & 3.2 & 1.4 \\
\hline A40-S50-E50 & 1400 & 2.5 & 1457 & 2.7 & 3.4 & 1191 & 3.3 & 4.6 & 4.8 & 2.0 \\
\hline A40-S75-E50 & 1437 & 2.5 & 1492 & 2.7 & 2.6 & 1190 & 3.4 & 5.1 & 3.9 & 1.6 \\
\hline
\end{tabular}

Note: ${ }^{a} \Delta_{0.75}$ represents the deformation corresponding axial load at $75 \%$ of the maximum axial load in the descending branch of the axial loadaxial deformation behavior

${ }^{\mathrm{b}}$ Calculated using Eq. (1). 
Table 6. Experimental Results of the Tested Specimens under Four-point Loading

\begin{tabular}{|c|c|c|c|c|c|c|}
\hline Specimen & $\begin{array}{c}\text { Yield } \\
\text { load } \\
P_{y} \\
(\mathrm{kN})\end{array}$ & $\begin{array}{c}\text { Deformation } \\
\text { at }\left(P_{y}\right) \\
(\mathrm{mm})\end{array}$ & $\begin{array}{l}\text { Maximum } \\
\text { Load } \\
\left(P_{\max }\right) \\
(\mathrm{kN})\end{array}$ & $\begin{array}{c}\text { Deflection at } \\
\left(P_{\max }\right) \\
(\mathrm{mm})\end{array}$ & $\begin{array}{l}\text { Deflection } \\
\Delta_{0.75}{ }^{\mathrm{a}} \\
(\mathrm{mm})\end{array}$ & Ductility $^{b}$ \\
\hline R-S50-F & 191 & 4.0 & 244 & 9.5 & 13.8 & 3.4 \\
\hline A30-S50-F & 206 & 4.8 & 260 & 9.5 & 21.7 & 4.6 \\
\hline A30-S75-F & 211 & 4.8 & 257 & 8.4 & 18.1 & 3.8 \\
\hline A40-S50-F & 424 & 7.8 & 491 & 11.8 & 28.5 & 3.7 \\
\hline A40-S75-F & 437 & 7.4 & 493 & 10.5 & 29.2 & 4.0 \\
\hline
\end{tabular}

Note: ${ }^{a} \Delta_{0.75}$ represents the deflection corresponding load at $75 \%$ of the maximum load in the descending branch of the load-midspan deflection behavior

${ }^{\mathrm{b}}$ Calculated using Eq. (1). 
Table 7. Experimental and Analytical Bending Moment Capacity of the Tested Specimens

\begin{tabular}{|c|c|c|c|c|c|c|c|c|}
\hline \multirow[b]{2}{*}{ Group } & \multirow[b]{2}{*}{ Specimen } & \multicolumn{3}{|c|}{ Experimental Results } & \multicolumn{2}{|c|}{ Analytical Results } & \multicolumn{2}{|c|}{$\frac{\text { Analytical }}{\text { Experimental }}$} \\
\hline & & $\begin{array}{l}\text { Axial } \\
\text { load } \\
(\mathrm{kN})\end{array}$ & $\begin{array}{c}\text { Deformation } \\
\text { at } P_{\max } \\
(\mathrm{mm})\end{array}$ & $\begin{array}{c}\text { Bending } \\
\text { moment } \\
(\mathrm{kN} . \mathrm{m})\end{array}$ & $\begin{array}{l}\text { Axial } \\
\text { load } \\
(\mathrm{kN})\end{array}$ & $\begin{array}{c}\text { Bending } \\
\text { moment } \\
(\mathrm{kN} . \mathrm{m})\end{array}$ & $\begin{array}{c}\text { Axial } \\
\text { load } \\
\%\end{array}$ & $\begin{array}{c}\text { Bending } \\
\text { moment } \\
\%\end{array}$ \\
\hline \multirow{4}{*}{ R-S50 } & R-S50-C & 2716 & 2.8 & - & 2627 & - & 97 & - \\
\hline & R-S50-E25 & 1967 & 2.7 & 52 & 1990 & 50 & 101 & 97 \\
\hline & R-S50-E50 & 1340 & 2.7 & 69 & 1389 & 69 & 104 & 100 \\
\hline & R-S50-F & 244 & 9.5 & 29 & - & 23 & - & 82 \\
\hline \multirow{4}{*}{ A30-S50 } & A30-S50-C & 2548 & 2.6 & - & 2557 & - & 100 & - \\
\hline & A30-S50-E25 & 1808 & 2.9 & 49 & 1937 & 48 & 107 & 98 \\
\hline & A30-S50-E50 & 1260 & 2.5 & 64 & 1340 & 67 & 106 & 105 \\
\hline & A30-S50-F & 260 & 9.5 & 31 & - & 19 & - & 63 \\
\hline \multirow{4}{*}{ A30-S75 } & A30-S75-C & 2749 & 2.6 & - & 2557 & - & 93 & - \\
\hline & A30-S75-E25 & 1457 & 2.8 & - & - & - & - & - \\
\hline & A30-S75-E50 & 1297 & 2.5 & 69 & 1340 & 67 & 103 & 99 \\
\hline & A30-S75-F & 257 & 8.4 & 30 & - & 19 & - & 63 \\
\hline \multirow{4}{*}{ A40-S50 } & A40-S50-C & 2977 & 2.7 & - & 2849 & - & 96 & - \\
\hline & A40-S50-E25 & 2032 & 2.8 & 53 & 2137 & 53 & 105 & 100 \\
\hline & A40-S50-E50 & 1457 & 2.7 & 78 & 1523 & 76 & 105 & 98 \\
\hline & A40-S50-F & 491 & 11.8 & 58 & - & 41 & - & 71 \\
\hline \multirow{4}{*}{ A40-S75 } & A40-S75-C & 2746 & 2.6 & - & 2849 & - & 104 & - \\
\hline & A40-S75-E25 & 1867 & 3.0 & 50 & 2137 & 53 & 114 & 106 \\
\hline & A40-S75-E50 & 1492 & 2.7 & 78 & 1523 & 76 & 102 & 97 \\
\hline & A40-S75-F & 493 & 10.5 & 58 & - & 41 & - & 71 \\
\hline
\end{tabular}




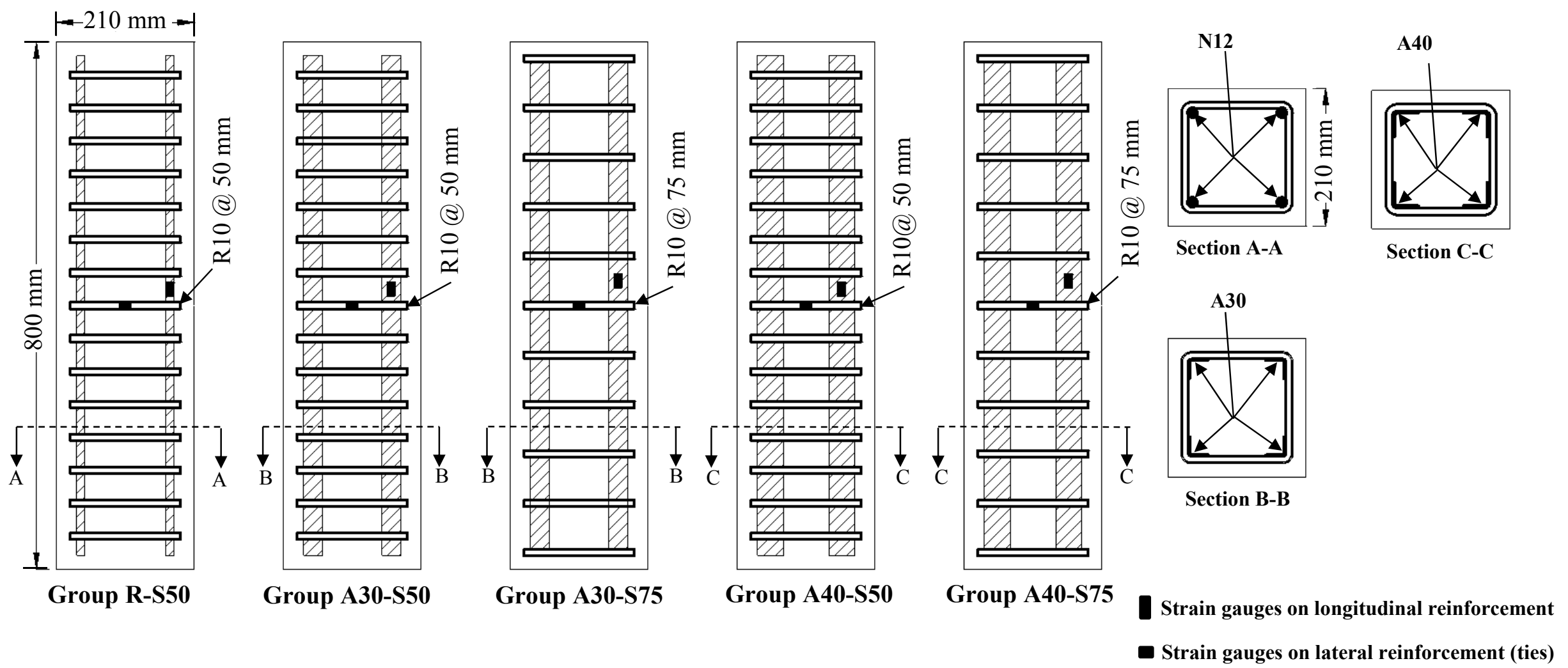

Fig. 1. Dimension and reinforcement arrangements of the test specimens 


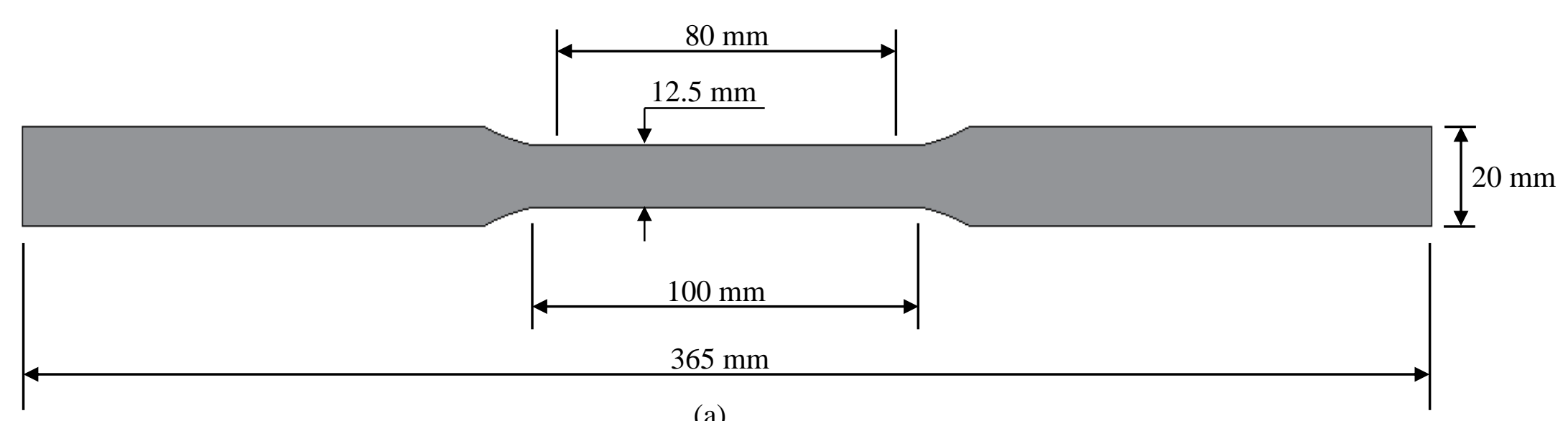

(a)

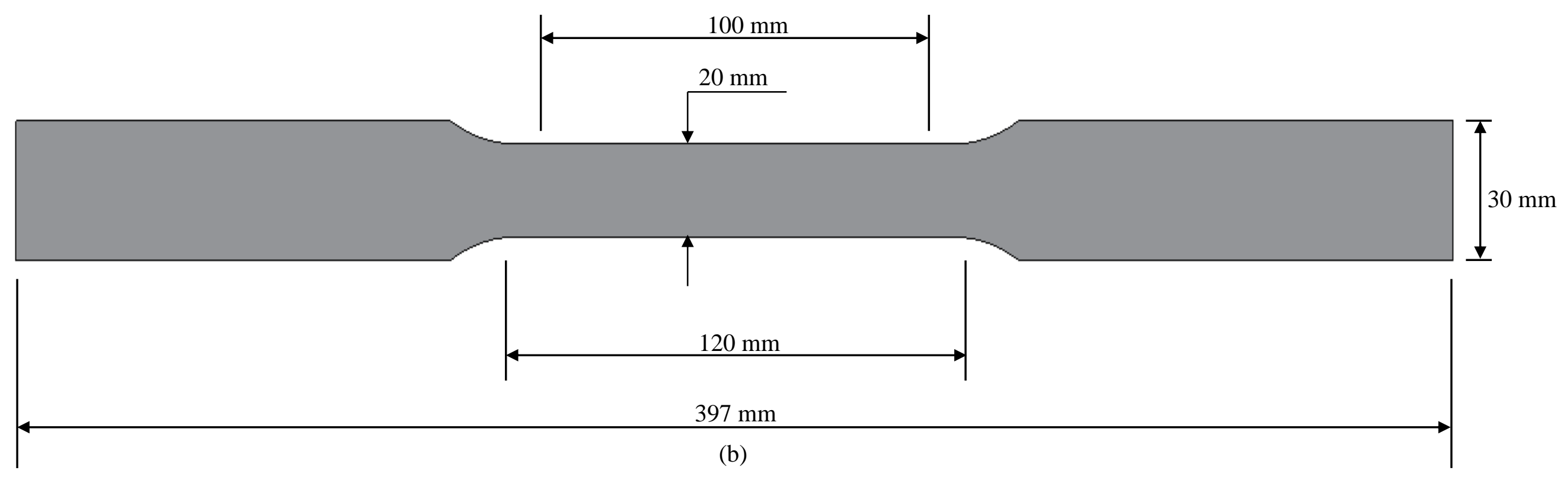

Fig. 2. Details of tensile coupon specimens of galvanized steel equal angle (GSEA) section: (a) A30; (b) A40 


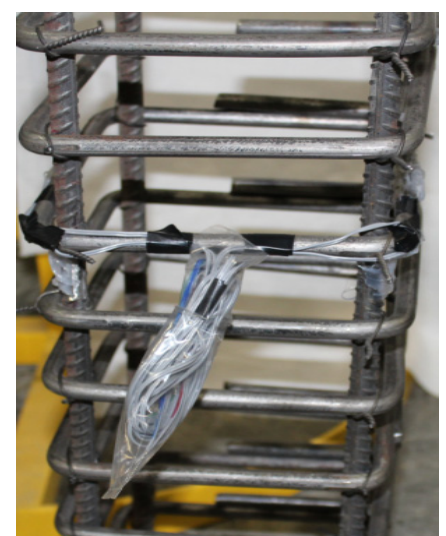

(a) Group R-S50

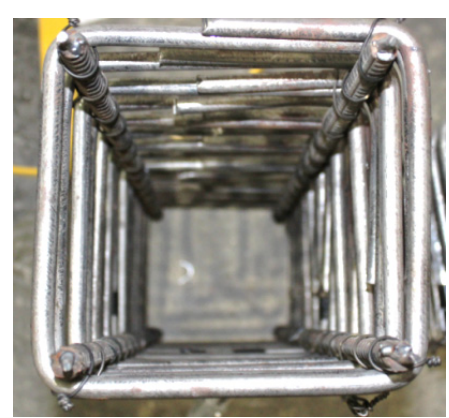

(f) Top view (R-S50)

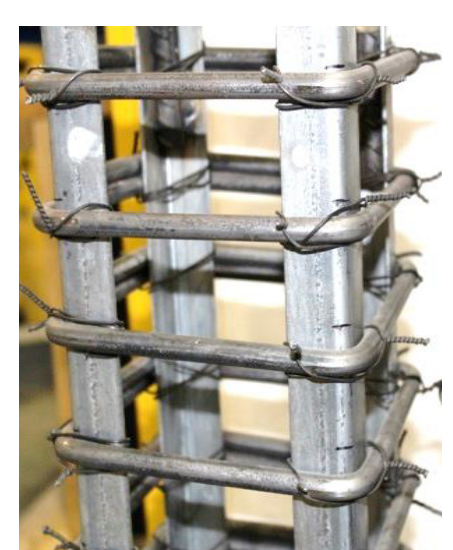

(b) Group A30-S50

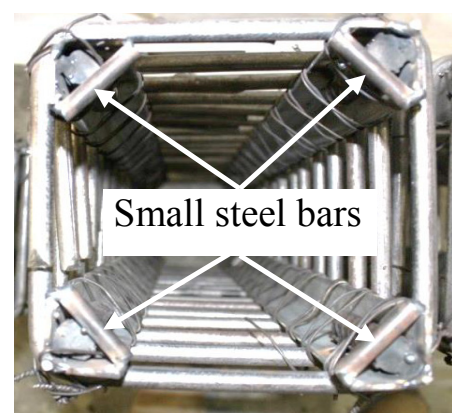

(g) Top view (A30-S50)

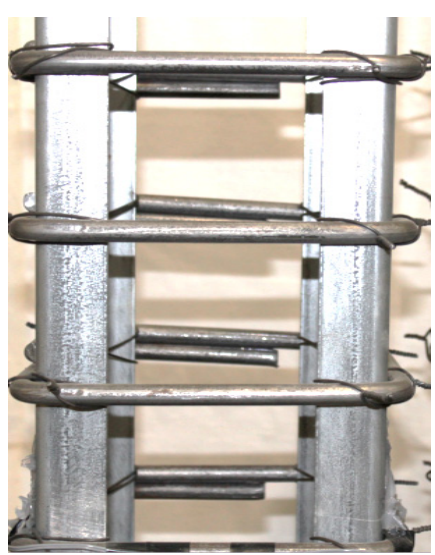

(c) Group A30-S75

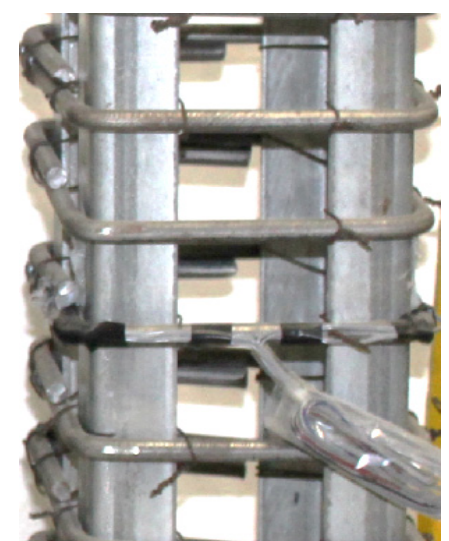

(d) Group A40-S50

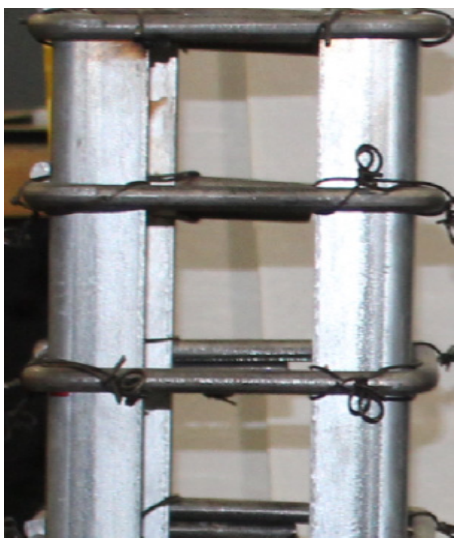

(e) Group A40-S75

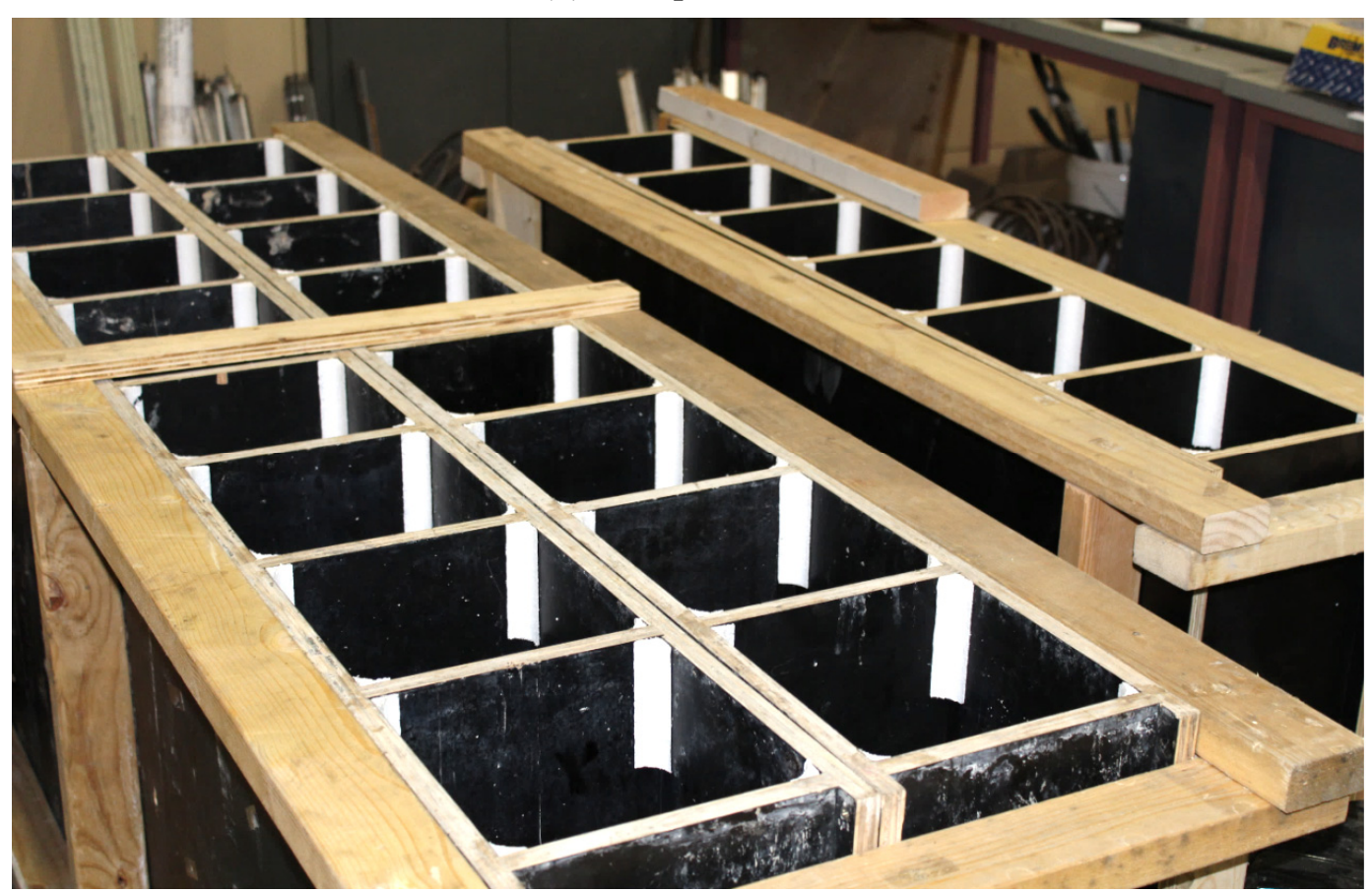

(i) Formwork

(h) Three welded points on the hook corner

Fig. 3. Overview of steel cages and formwork for tested specimens 


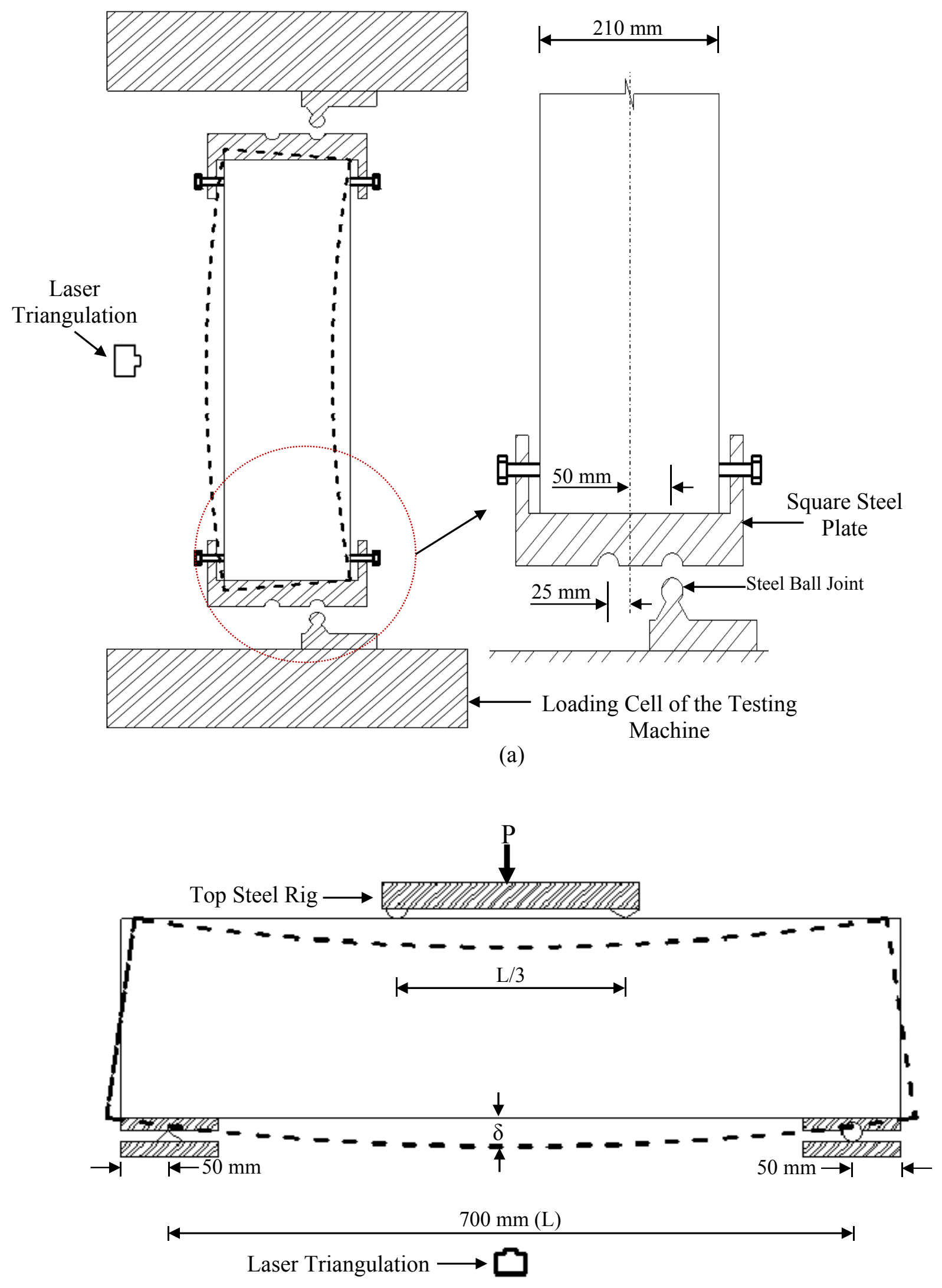

(b)

Fig. 4. Testing of specimens: (a) Specimen under eccentric axial load; (b) Specimen under fourpoint loading 

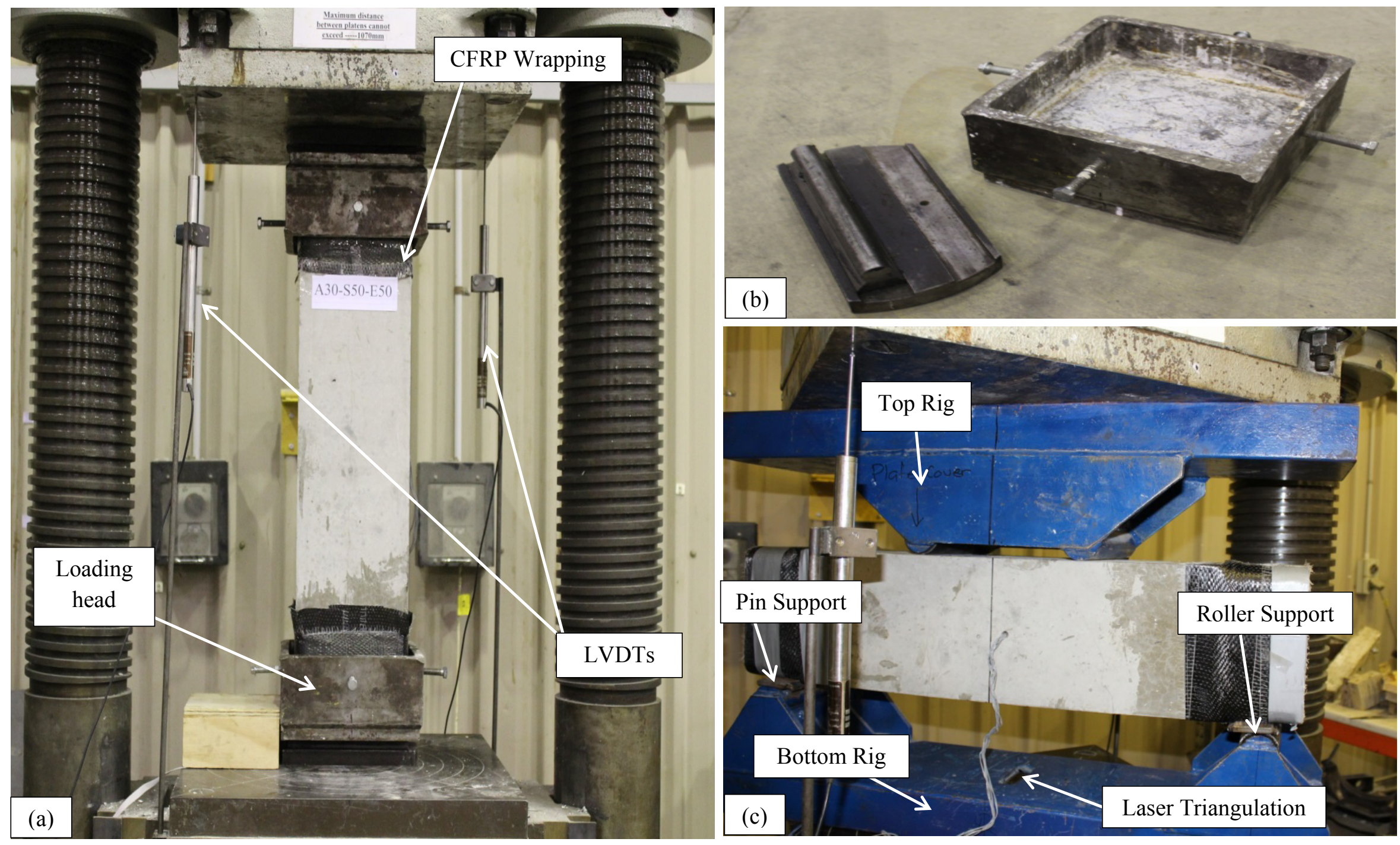

Fig. 5. Typical testing setup: (a) Specimen under axial compression; (b) Loading head and eccentric load system; (c) Specimen under four-point loading 


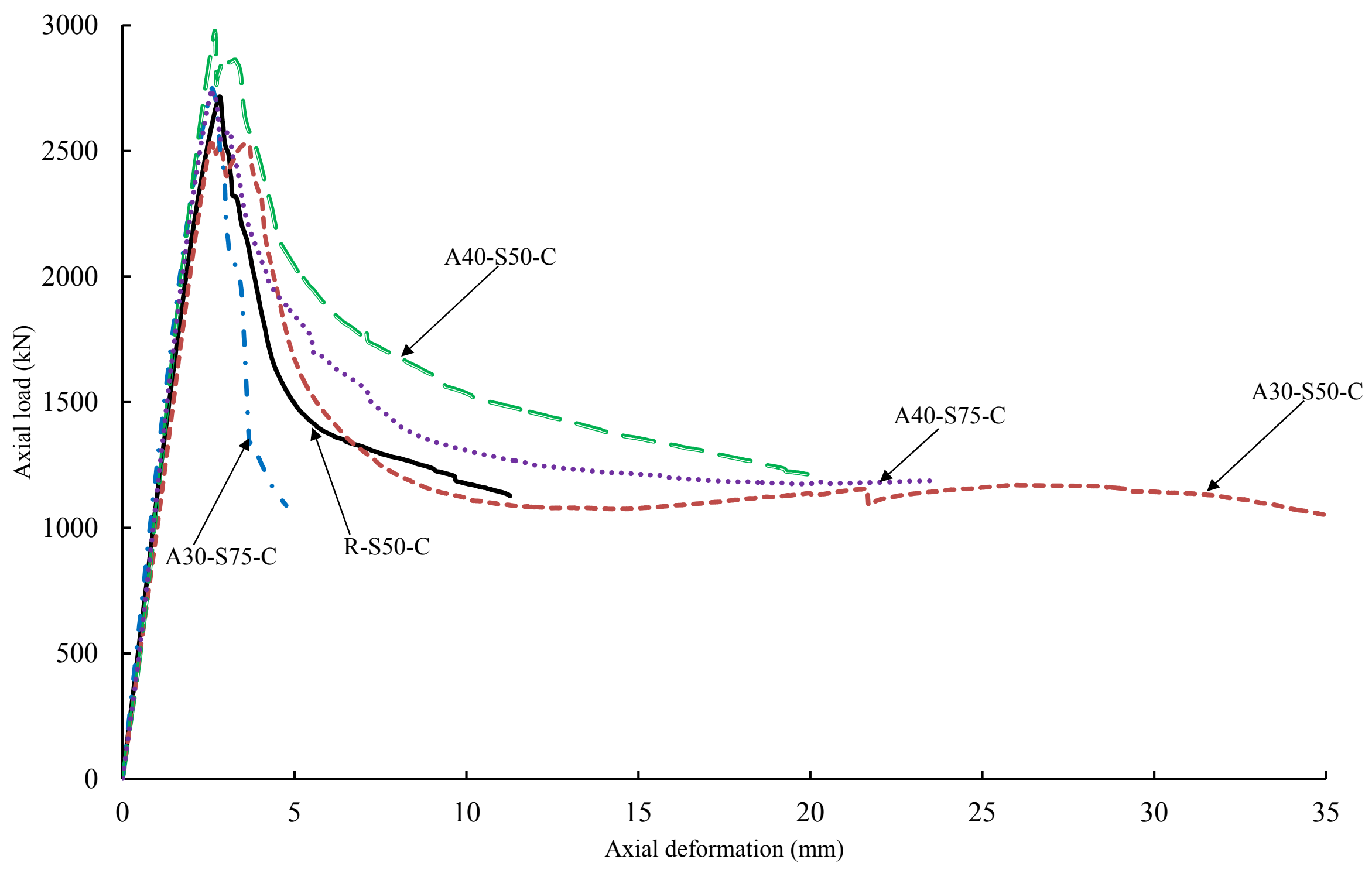

Fig. 6. Axial load-axial deformation response of specimens tested under concentric axial load 


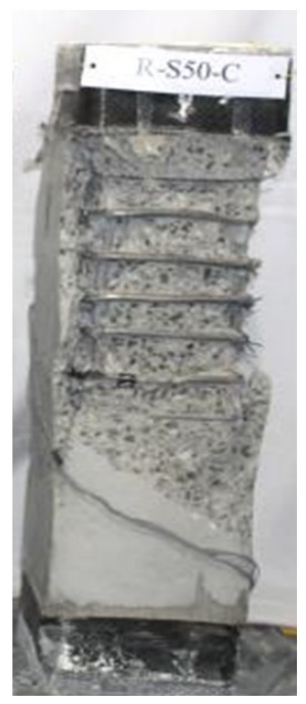

R-S50-C

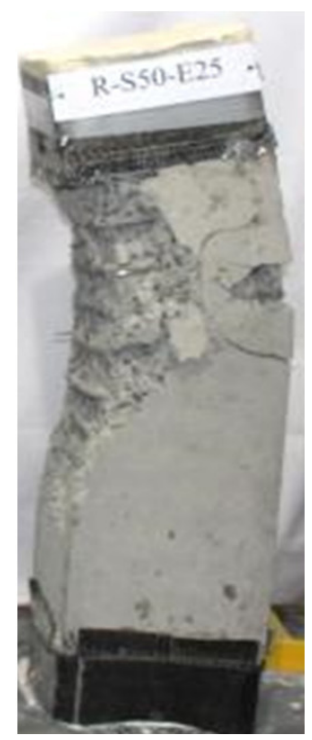

R-S50-E25

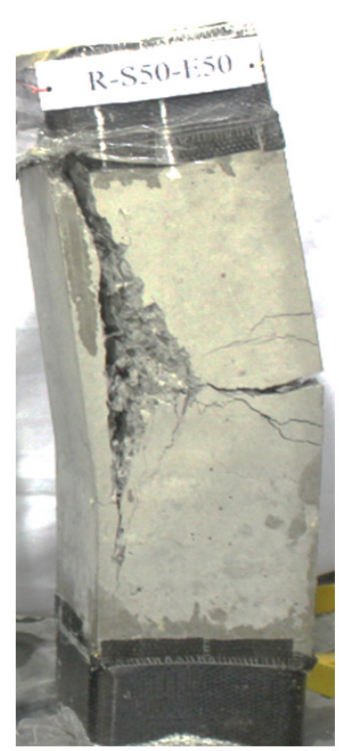

R-S50-E50

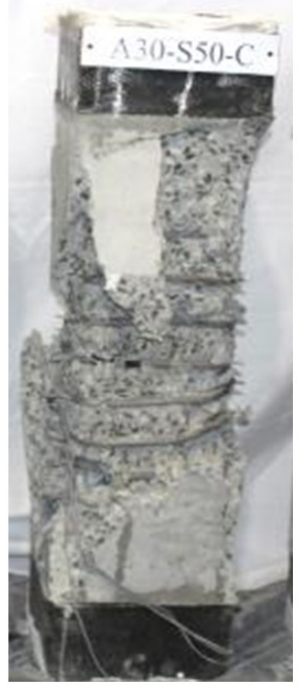

A30-S50-C

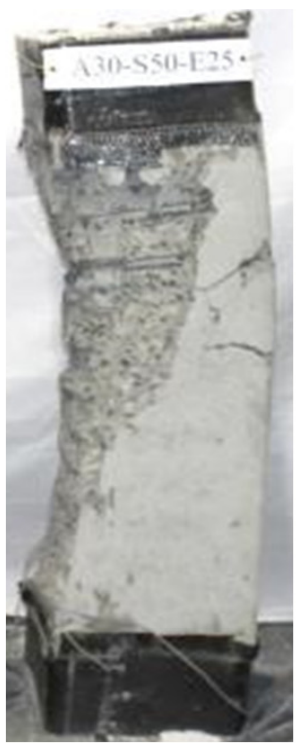

A30-S50-E25

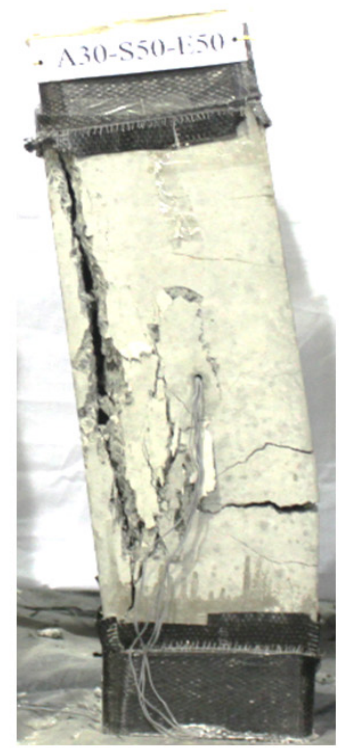

A30-S50-E50

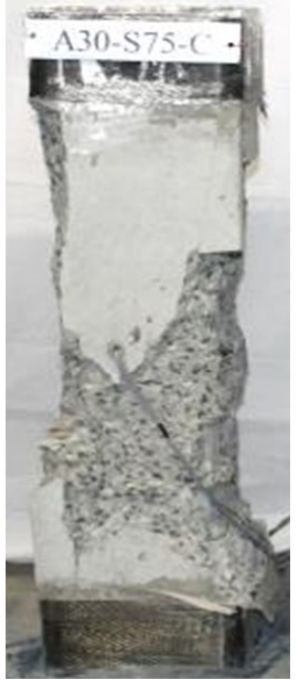

A30-S75-C

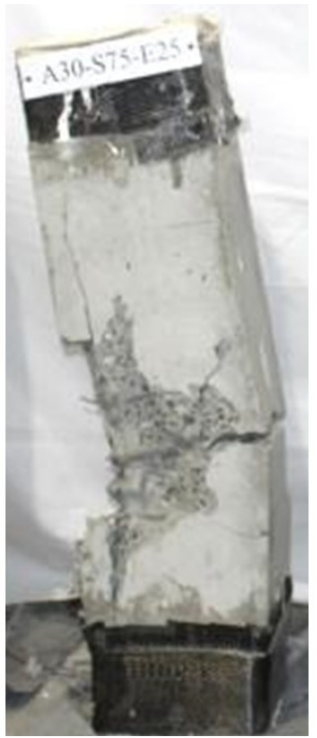

A30-S75-E25

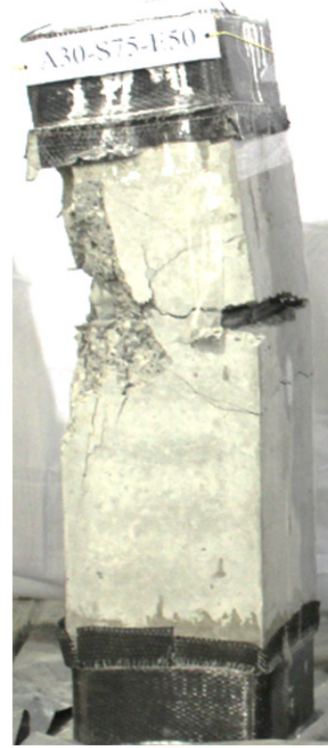

A30-S75-E50

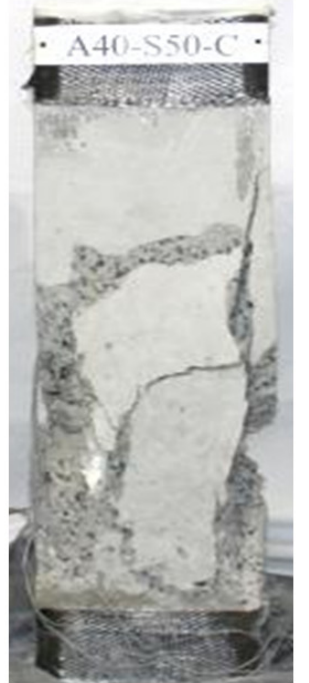

A40-S50-C

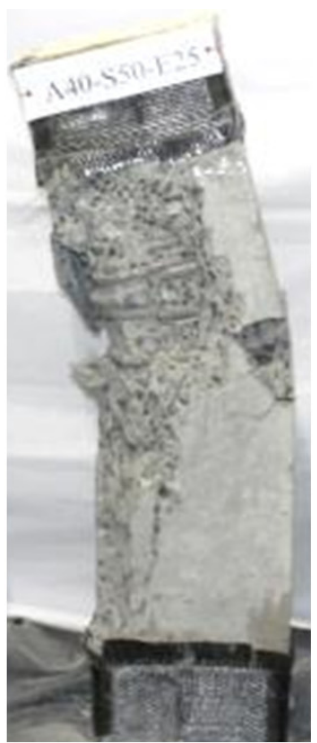

A40-S50-E25

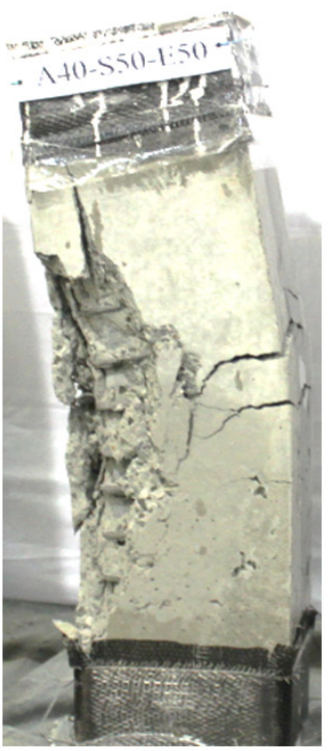

A40-S50-E50

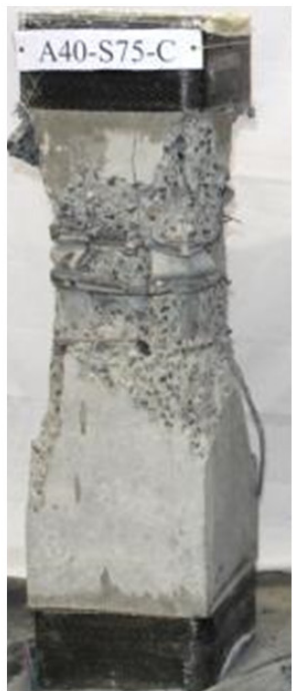

A40-S75-C

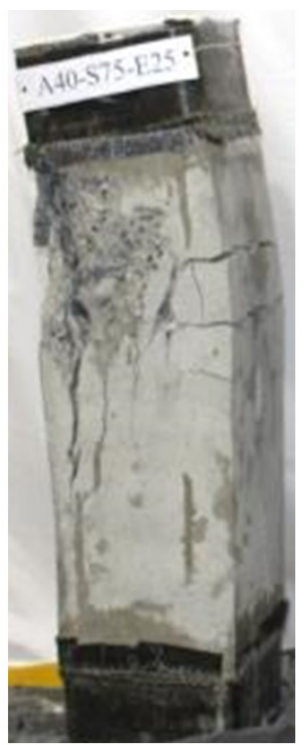

A40-S75-E25
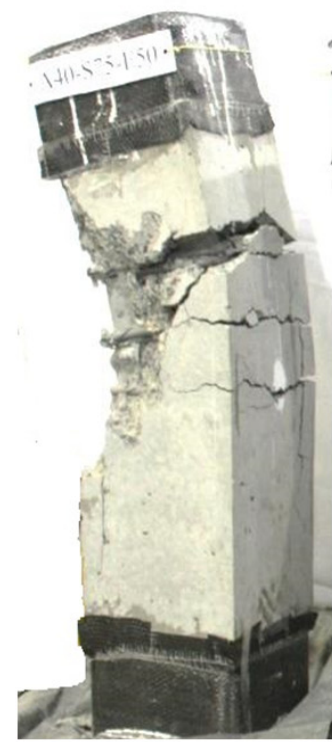

A40-S75-E50

Fig. 7. Failure modes of the tested specimens under axial compression 


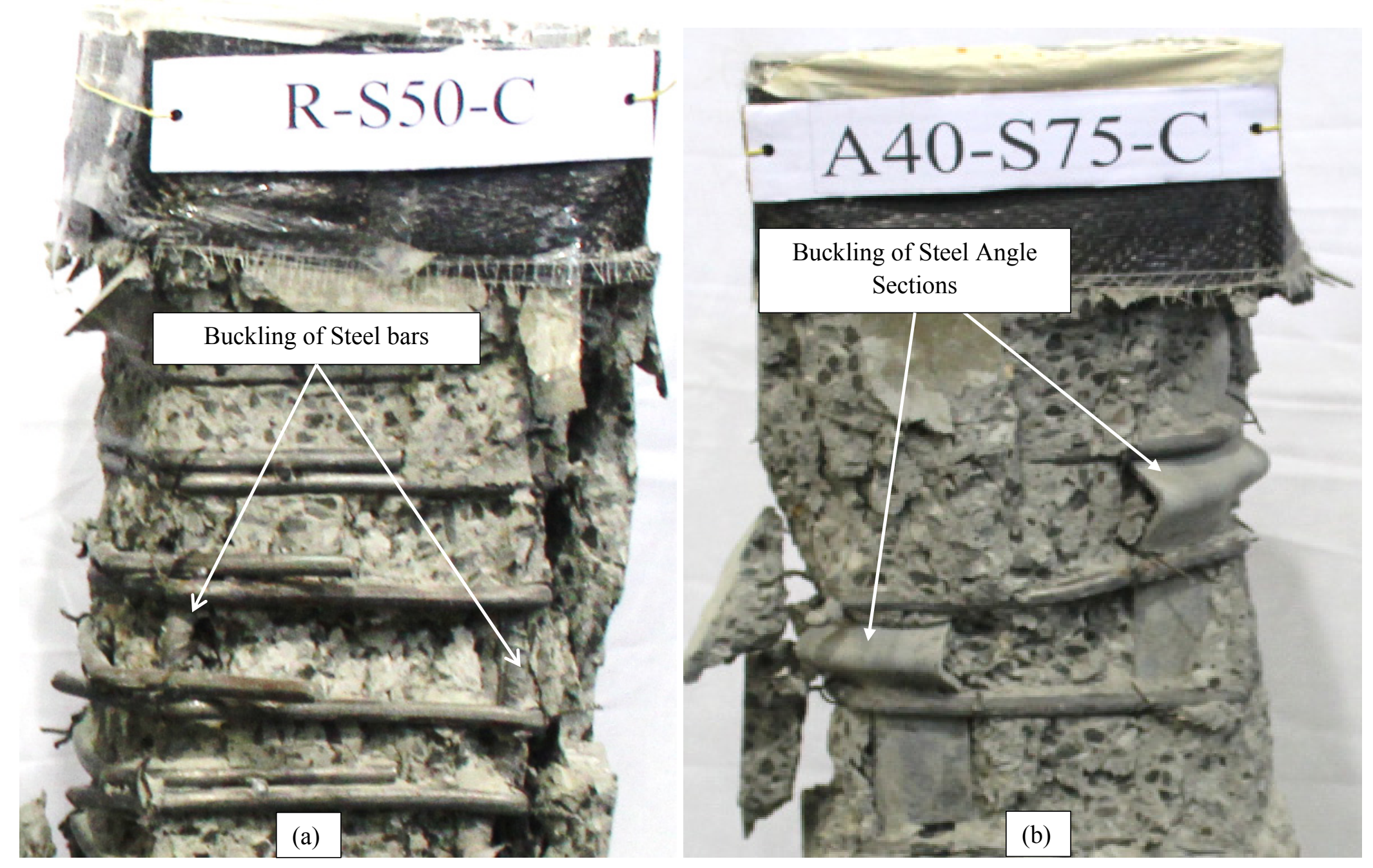

Fig. 8. Close-up view of the typical failure under concentric axial load: (a) R-S50-C; (b) A40-S75-C 


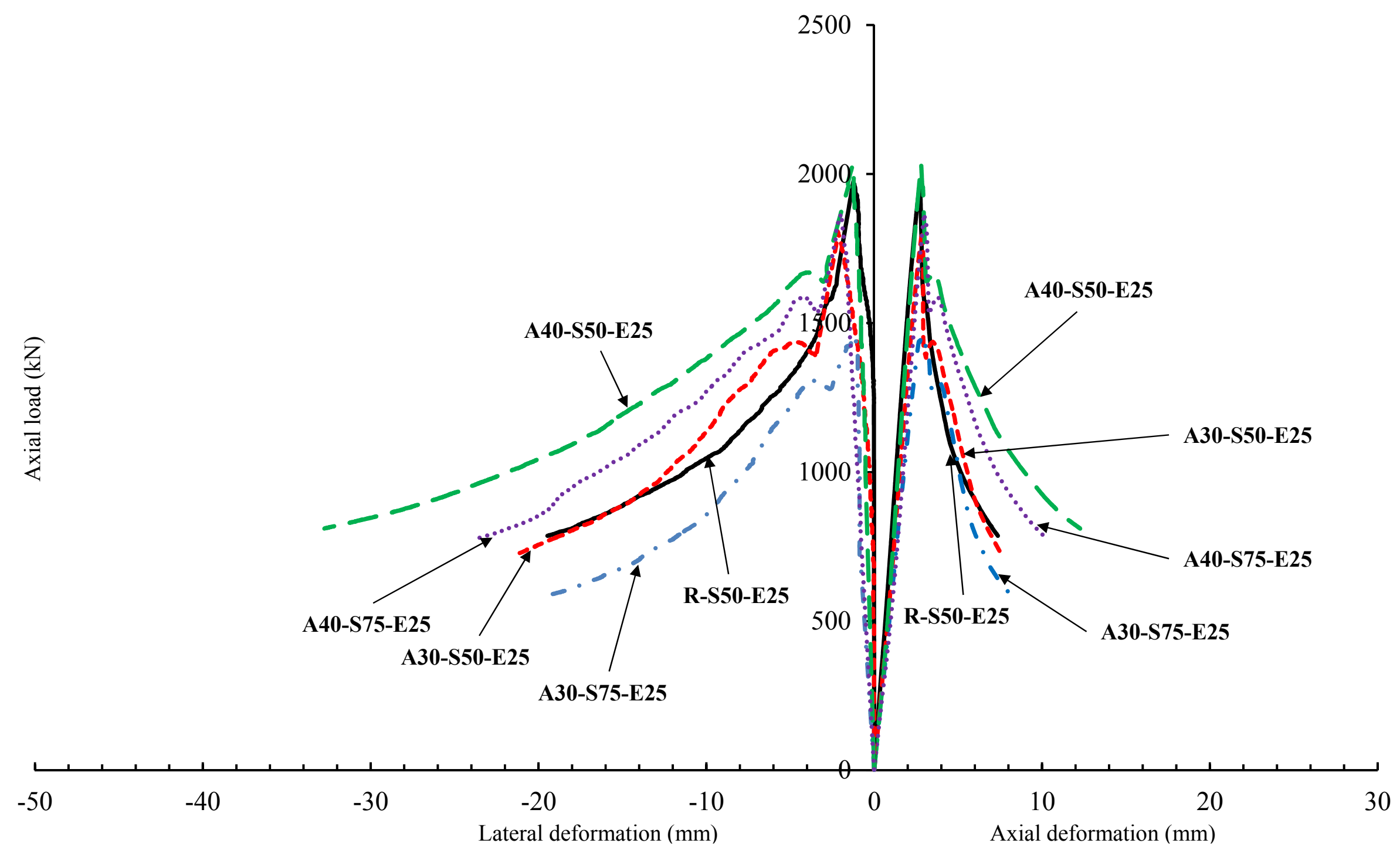

Fig. 9. Axial load-axial deformation and axial load-lateral deformation response of specimens tested under $25 \mathrm{~mm}$ eccentric axial load 


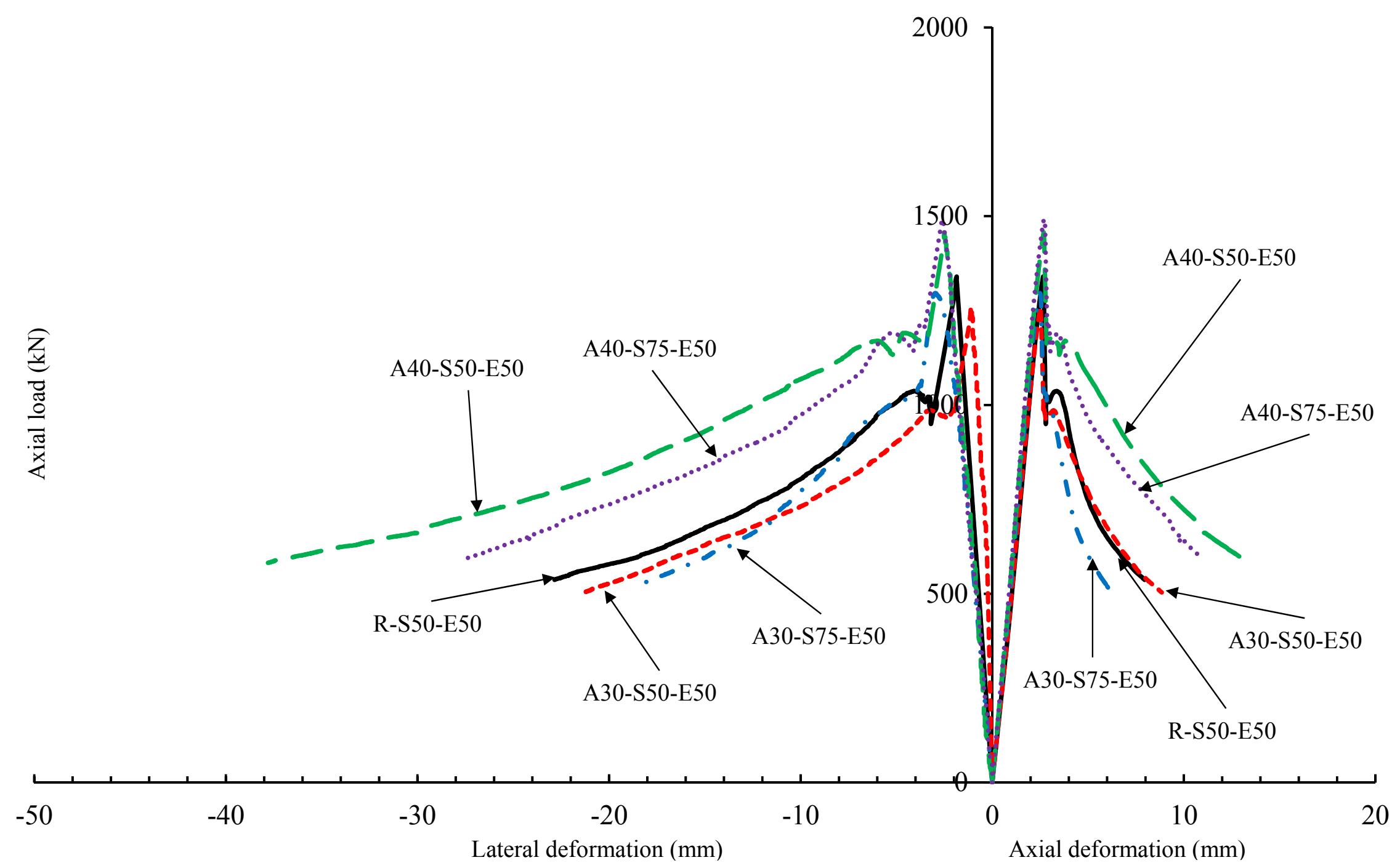

Fig. 10. Axial load-axial deformation and axial load-lateral deformation response of specimens tested under $50 \mathrm{~mm}$ eccentric axial load 


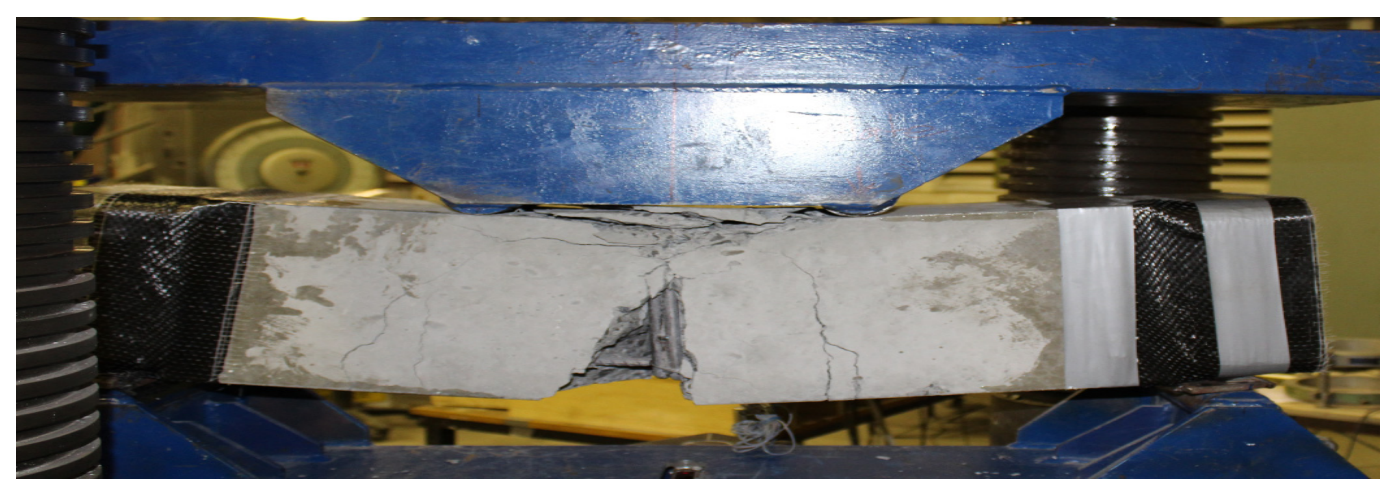

(a) R-S50-F

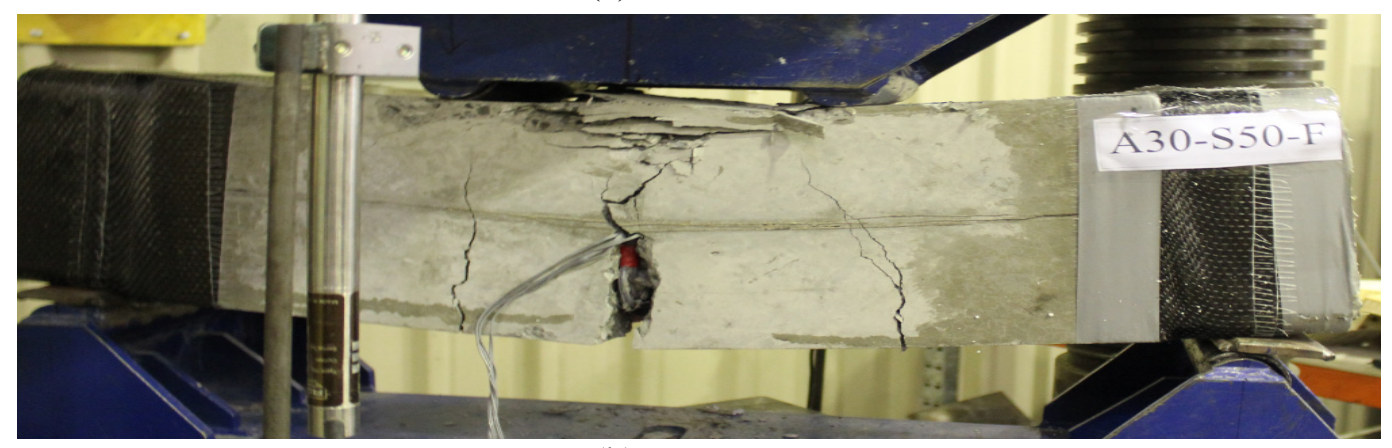

(b) A30-S50-F

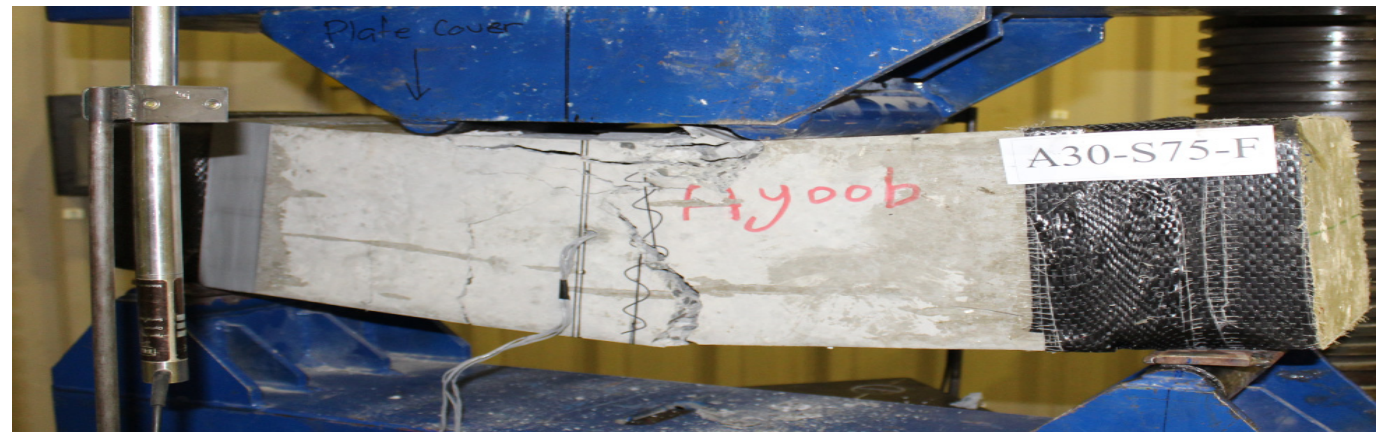

(c) A30-S75-F

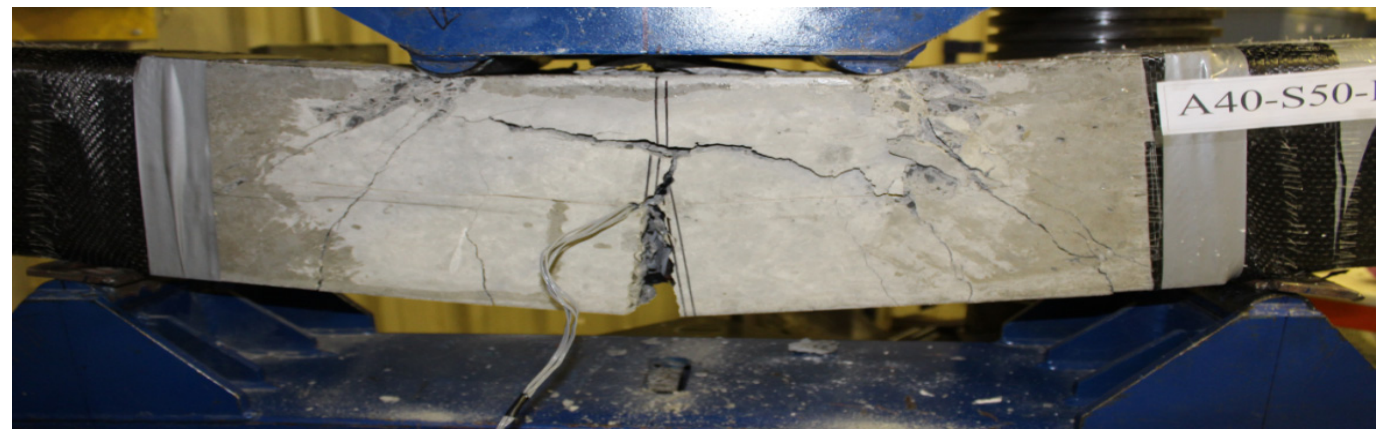

(d) A40-S50-F

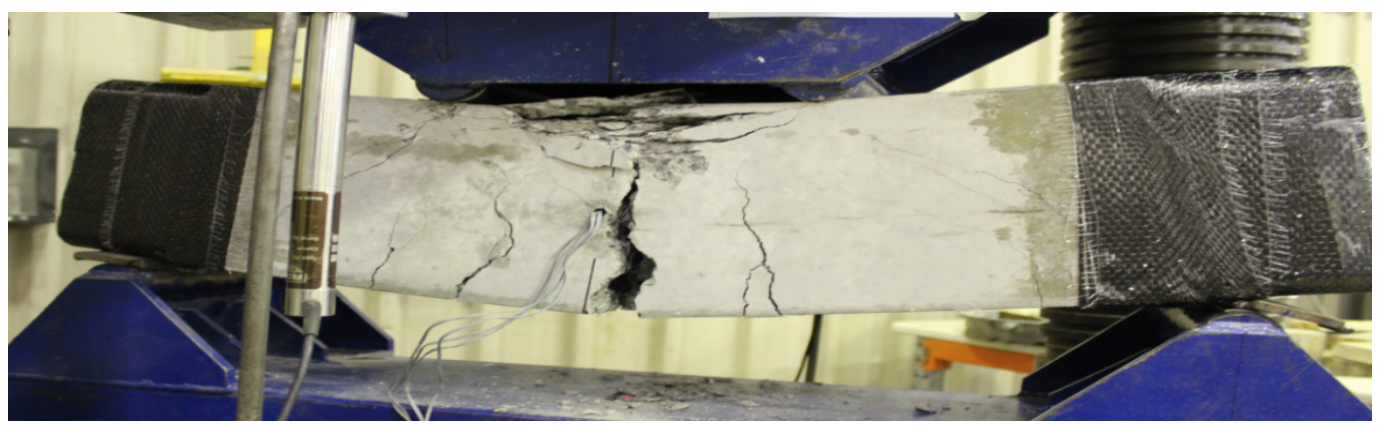

(e) A40-S75-F

Fig. 11. Failure modes of the tested specimens under four-point loading 


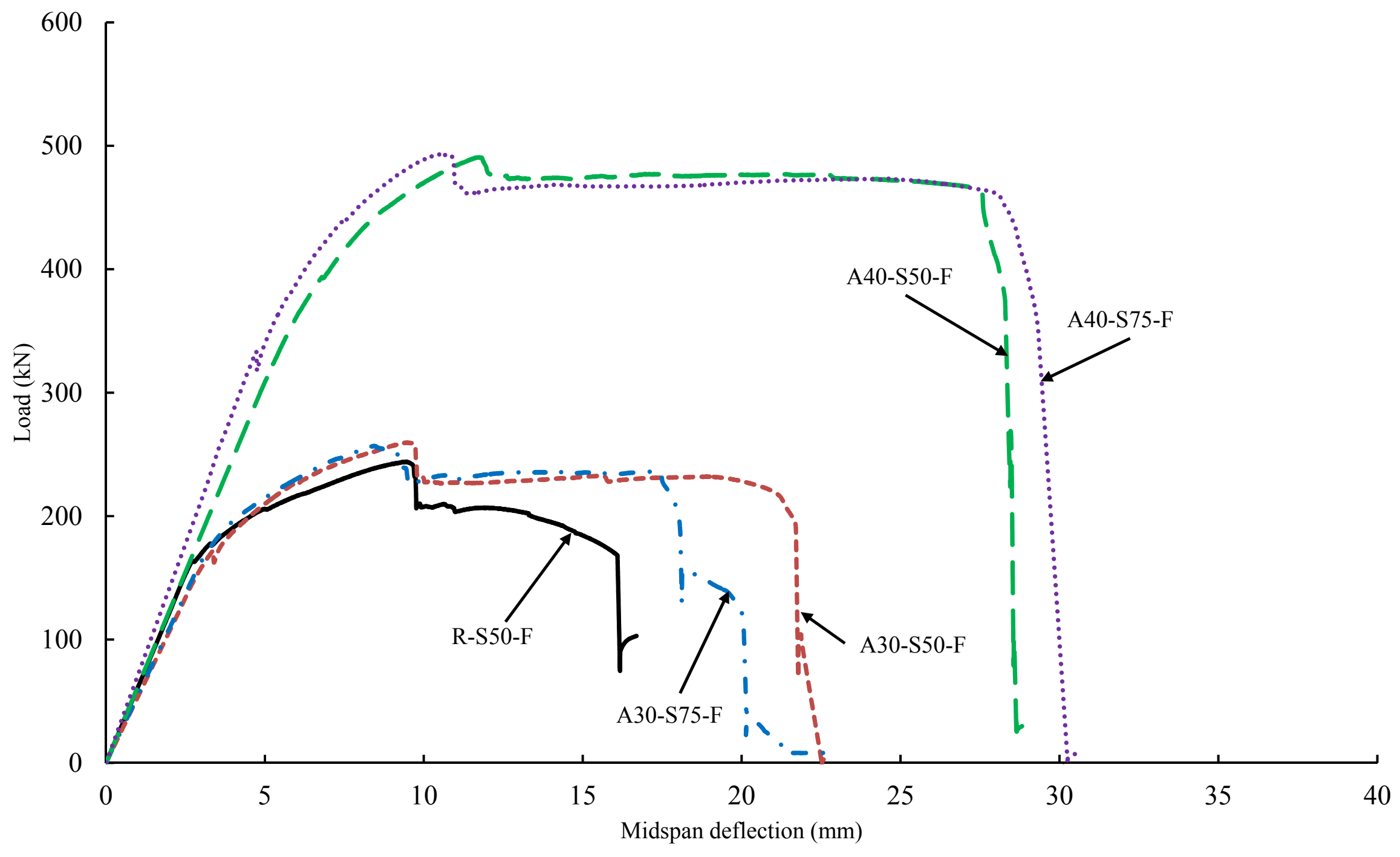

Fig. 12. Load-midspan deflection behavior of specimens tested under four-point loading 


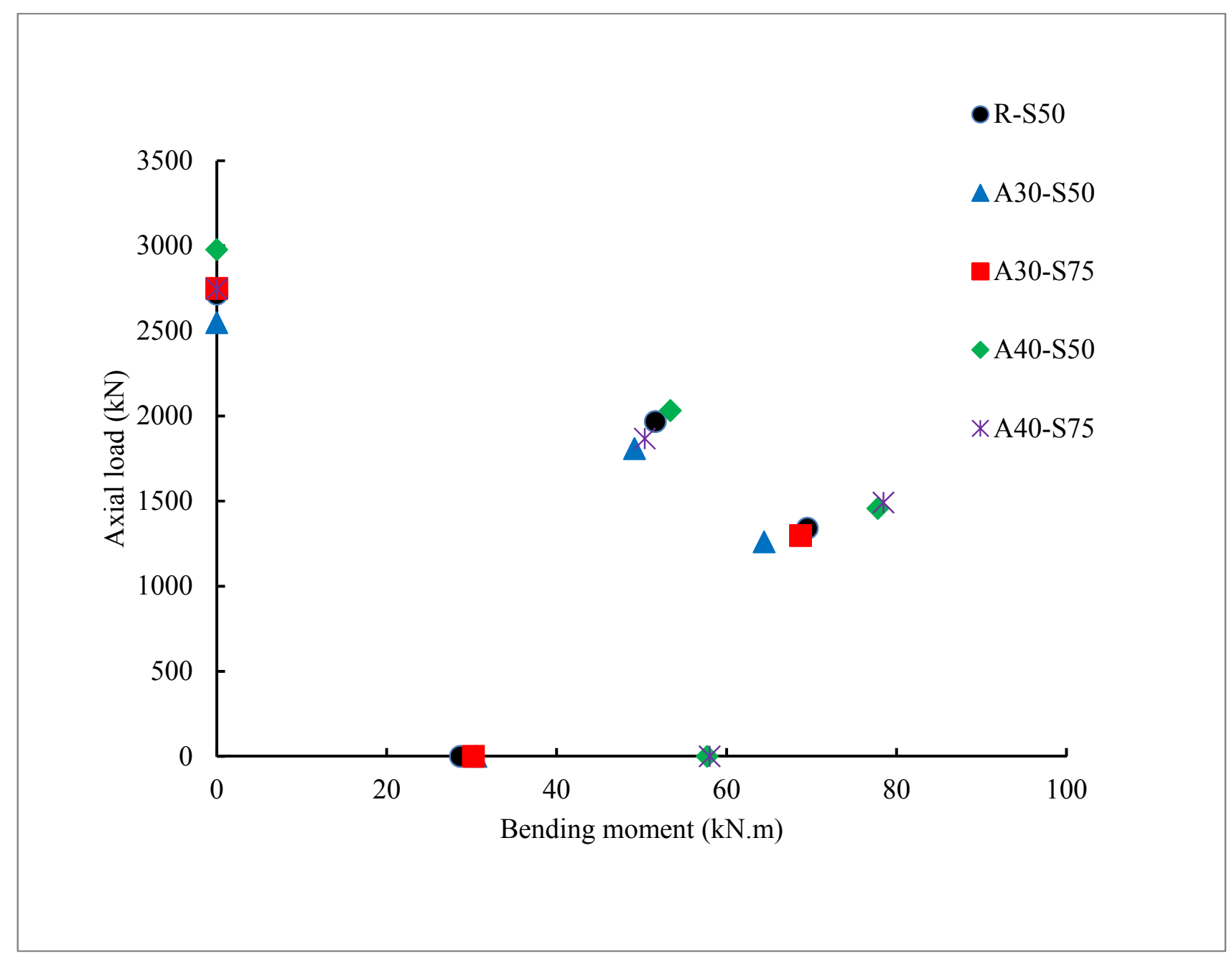

Fig. 13. Experimental axial load-bending moment $(P-M)$ interactions of tested specimens 


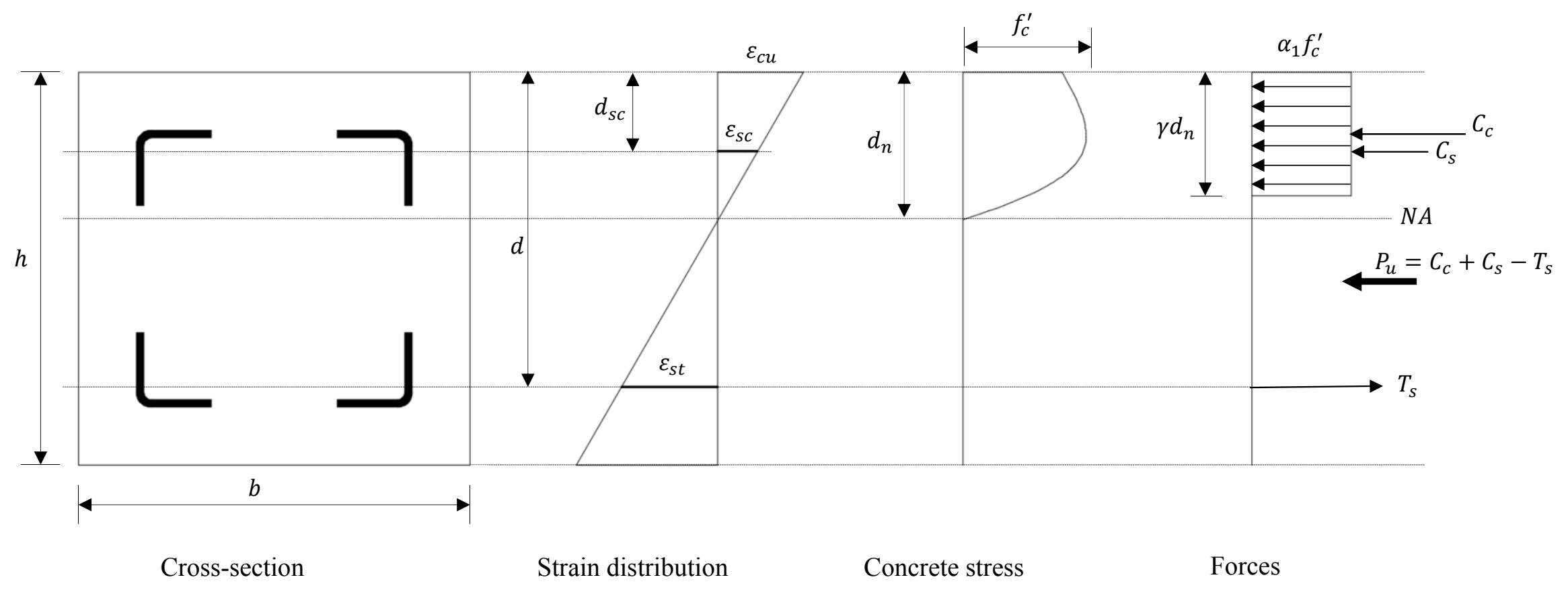

Fig. 14. Stress-strain distribution and force equilibrium of specimens under eccentric axial compression 


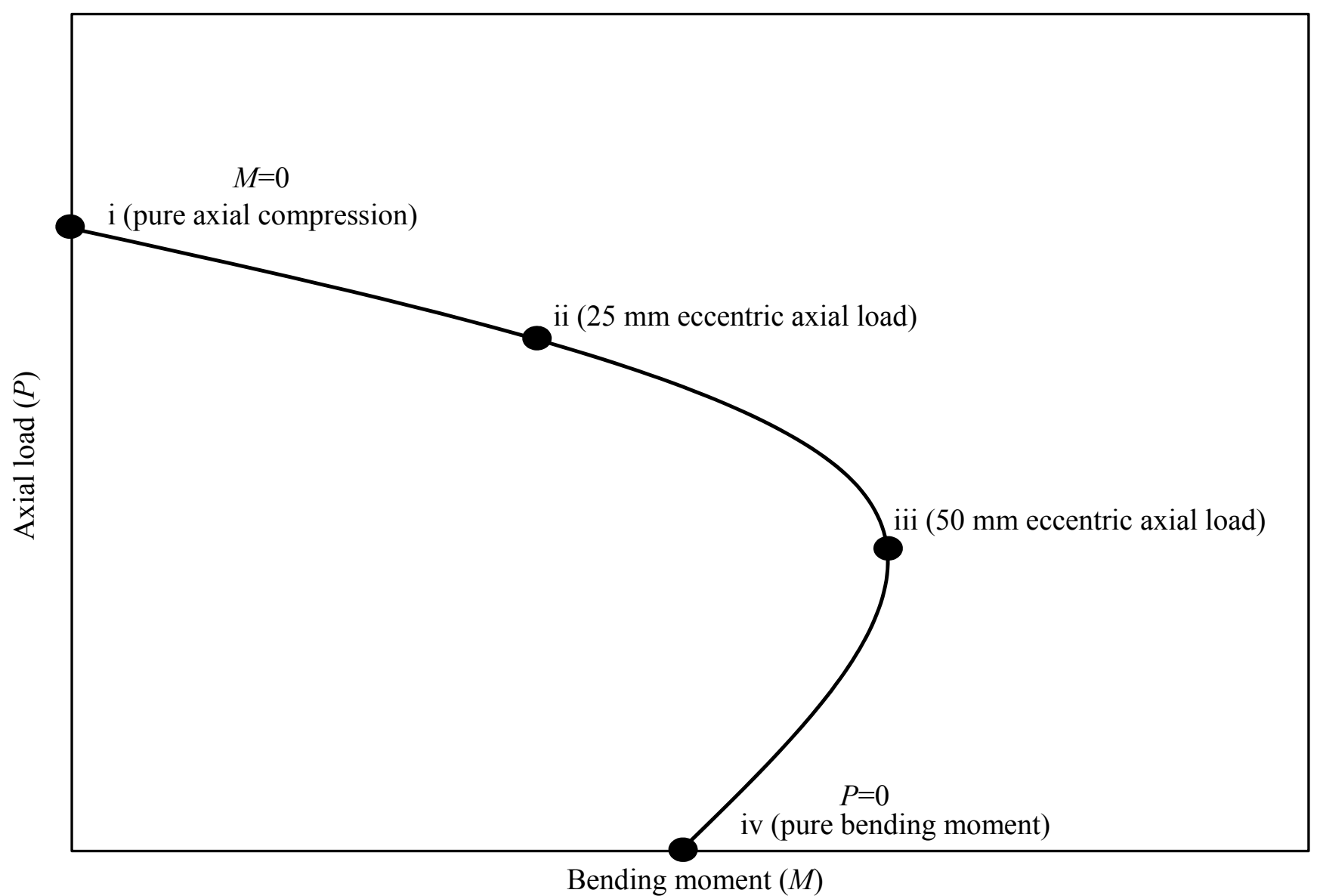

Fig. 15. $P-M$ interaction diagram 


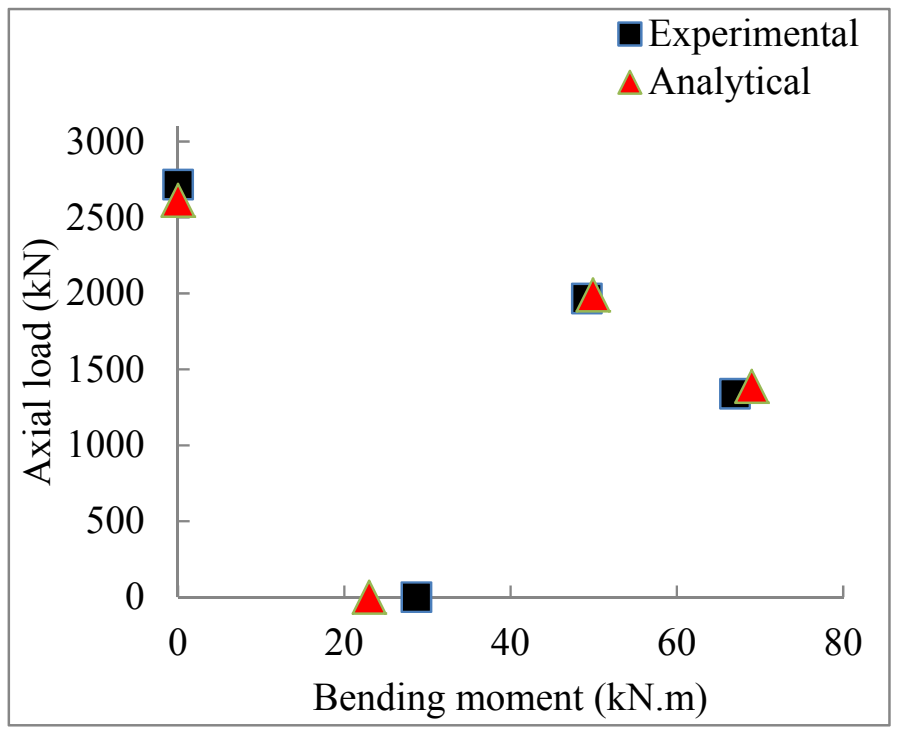

(a) Group R-S50

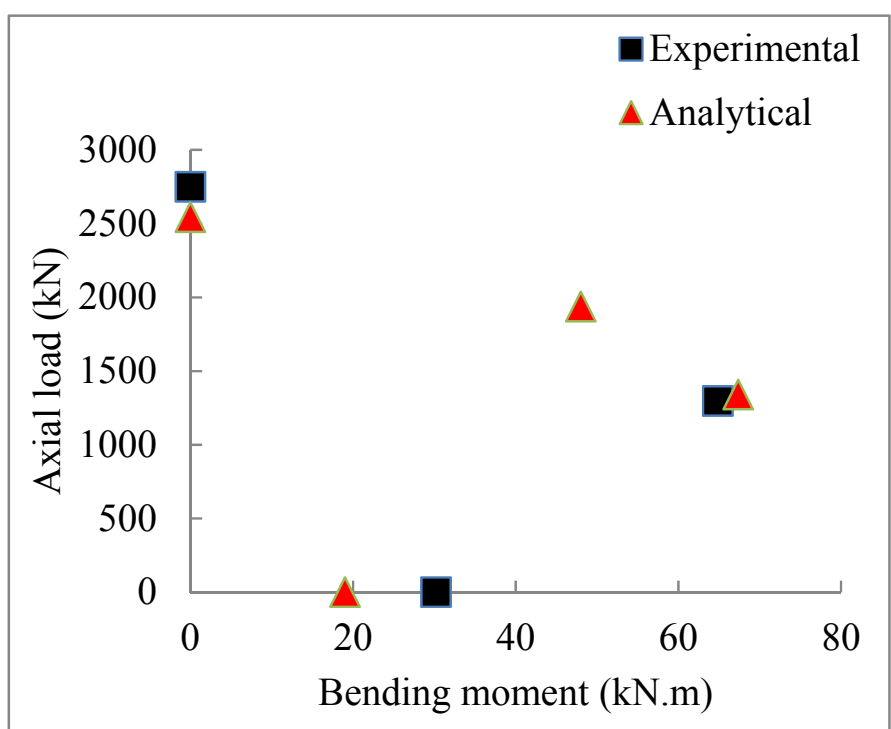

(c) Group A30-S75

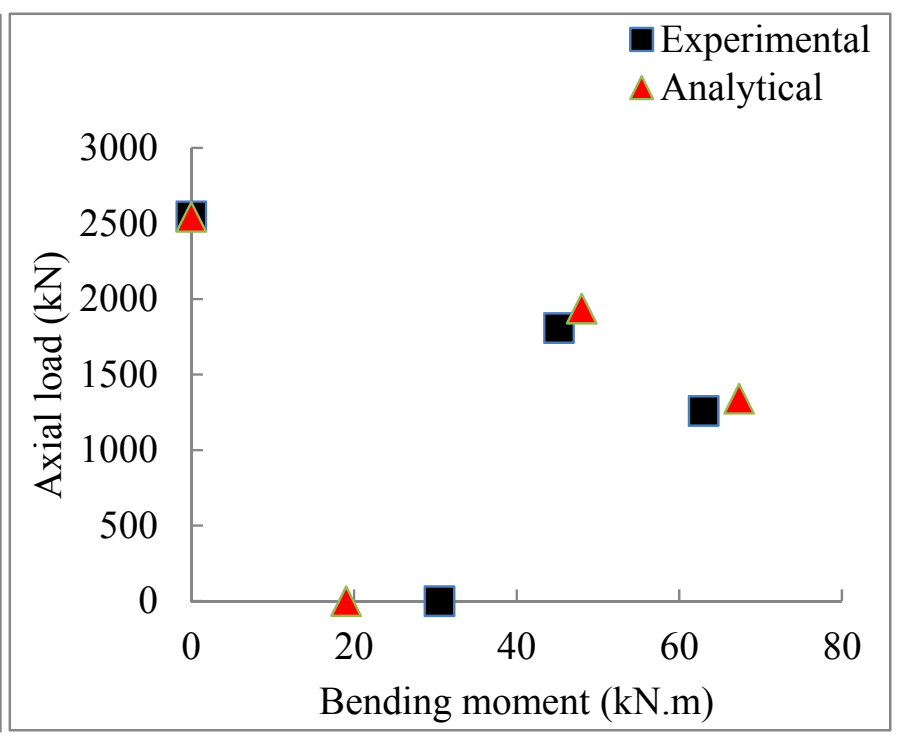

(b) Group A30-S50

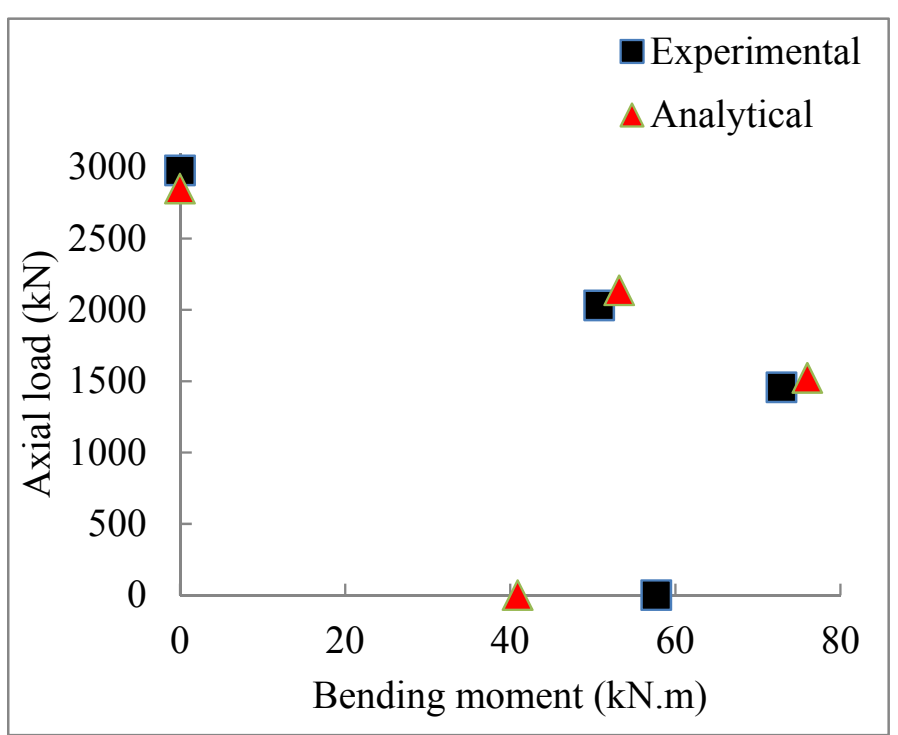

(d) Group A40-S50

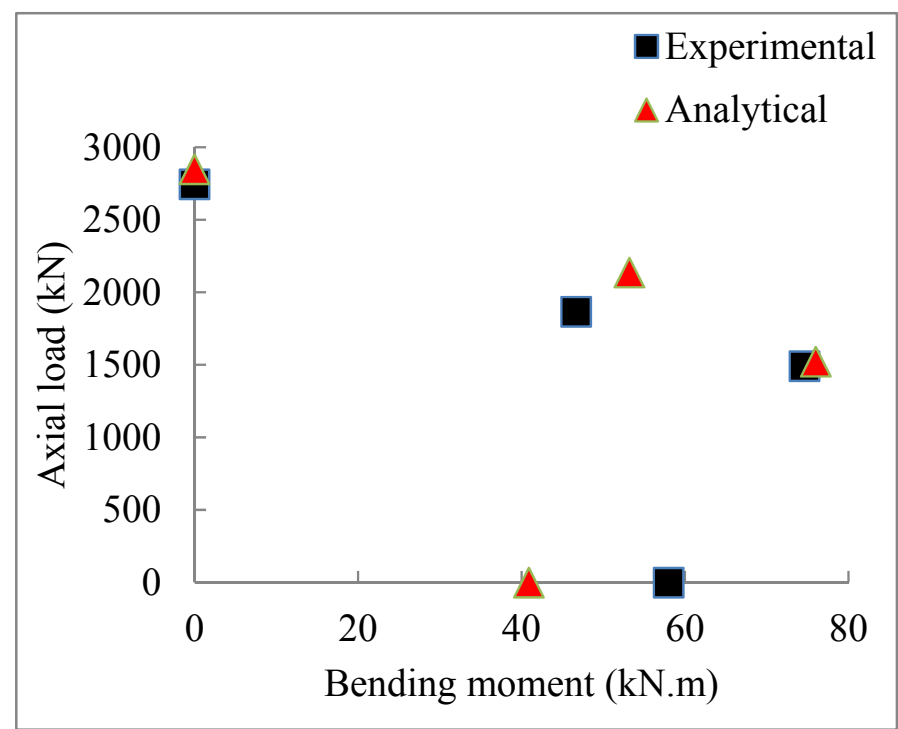

(e) Group A40-S75

Fig. 16. Experimental and analytical axial load-bending moment $(P-M)$ interactions of tested specimens 